\title{
Desigualdades de oportunidades educacionais dos adolescentes no Brasil e no México
}

\author{
Letícia J. Marteleto* \\ Flavio Carvalhaes ** \\ Celia Hubert ${ }^{\star \star *}$
}

\begin{abstract}
O objetivo desse artigo é examinar tendências recentes da estratificação educacional para adolescentes do Brasil e México em três períodos distintos: a década de 1980, de severa recessão; os anos 1990, um período de ajustes estruturais; e os anos 2000, década de crescimento. Além de matrículas escolares e probabilidades de transições educacionais, é examinada também a matrícula em escolas particulares, um aspecto importante da desigualdade educacional pouco abordado em estudos sobre o tema. Foram utilizados dados das PNADs para o Brasil e ENIGH para o México. Os resultados confirmam importantes benefícios trazidos pelas condições favoráveis recentes e pela universalização do ensino fundamental, mas também identificam crescentes desvantagens associadas ao acesso à escola particular, o que sugere a importância da perspectiva EMI (Effectively Maintained Inequality). O estudo enfatiza a importância de analisar a qualidade além da quantidade de ensino formal para uma compreensão mais profunda da estratificação educacional.
\end{abstract}

Palavras-chave: Desigualdade educacional. Juventude. Brasil. México.

\section{Introdução}

Pesquisas recentes mostraram que as tendências nas desigualdades de oportunidades educacionais na América Latina contrastam com experiências de outros países industrializados (TORCHE, 2010). Países latino-americanos exibiram um padrão de fortalecimento da associação entre origem socioeconômica dos pais e a realização educacional de coortes que cresceram durante os anos 1980, o que foi atribuído à crise econômica durante a "década perdida"1 (TORCHE, 2010). Os anos 1980 foram um período peculiar na América Latina devido ao agravamento da crise da dívida externa e ajustes estruturais (THORP, 1998; CARRASCO, 1999). Durante esse período, a região vivenciou uma acentuada desaceleração da escolarização (BEHRMAN; DURYEA; SZEKELY, 1999) e as desigualdades de oportunidade de curto e longo prazos aumentaram. A reação dos pais às altas taxas de desemprego

\footnotetext{
${ }^{*}$ Ph.D. em Sociologia com concentração em Demografia, pela Universidade de Michigan, professora do Departamento de Sociologia e Population Research Center da Universidade do Texas-Austin, investigadora principal no National Institute of Health (NIH).

** Doutorando em Sociologia no Instituto de Estudos Sociais e Políticos da Universidade do Estado do Rio de Janeiro (IESP-UERJ).

*** Doutoranda em Sociologia na Universidade do Texas-Austin.

${ }^{1}$ A década de 1980 é geralmente referida como a "década perdida" devido ao baixo crescimento e ao fato de que a renda per capita familiar no fim da década era menor do que no início.
} 
foi, muitas vezes, tirar os filhos da escola e mandá-los para o mercado de trabalho informal (DURYEA; LAM; LEVISON, 2007), o que levou a um aumento da desigualdade de oportunidades educacionais no longo prazo, particularmente para crianças em famílias de baixa renda (TORCHE, 2010). As consequências do período de estagnação econômica foram tão fortes que Behrman e seus colaboradores $(1999$, p. 10, tradução nossa) colocam que "ao menos que exista um aumento substancial na acumulação da escolaridade após as idades de 15 a 18 anos, o que não é provável, o desaceleramento da acumulação da escolaridade continuaria e, provavelmente, se intensificaria".

Após períodos de baixo crescimento econômico, vários países latino-americanos mostraram significativa estabilidade econômica e crescimento nos anos 2000 . Apesar de a desigualdade ainda ser alta, particularmente em relação a outras nações com o mesmo Produto Interno Bruto (PIB), muitos países da região mostraram sinais de desigualdade decrescente, medida pelo coeficiente de Gini (LOPEZ-CALVA; LUSTIG, 2010). Ao mesmo tempo, ao longo das décadas de 1990 e 2000, a região passou por uma expansão educacional sem precedentes, com a maioria dos países - mais notadamente Brasil e México - atingindo taxas de matrículas que indicavam uma virtual universalização do ensino fundamental, com crescentes taxas de matrícula para os níveis posteriores de ensino (VELOSO, 2009).

O objetivo deste artigo é, portanto, examinar mudanças nas desigualdades de oportunidades educacionais para coortes de adolescentes no Brasil e no México. Comparar as desigualdades de oportunidades educacionais nesses países é interessante porque Brasil e México tiveram, tradicionalmente, níveis de escolaridade relativamente baixos se comparados a Argentina, Chile e Uruguai, por exemplo. São analisadas as tendências de estratificação educacional para adolescentes em três períodos distintos: a década de 1980, durante recessão severa; a década de 1990, um período de ajustes estruturais impostos por organizações internacionais; e o os anos 2000, quando os dois países viveram períodos de crescimento relativamente estáveis. Analisamos, primeiramente, a matrícula escolar e transições educacionais, além de identificarmos diferenças na qualidade da educação por meio das matrículas em escolas particulares, um aspecto importante da desigualdade educacional que a maioria dos estudos nesta área negligenciou até o momento.

\section{Tendências recentes dos contextos econômicos, sociais e educacionais no Brasil e México}

A Tabela 1 apresenta indicadores sociais, econômicos e educacionais para o Brasil e México, no período de 1985 a 2005. Os baixos níveis do PIB per capita em ambos países ilustram as condições desfavoráveis da "década perdida". Com exceção da crise de 1995 no México, os dois países vivenciaram um significativo crescimento econômico ao longo dos anos 1990, medido pelo PIB per capita. A Tabela 1 também mostra que o crescimento econômico dos anos 2000 é associado a um leve decréscimo das desigualdades medidas pelo coeficiente de Gini, o qual aumentou entre 1985 e 1995 no Brasil, mas diminuiu nos anos 2000 (LOPEZ-CALVA; LUSTIG, 2010). Essa queda sugere que pode ter ocorrido melhoria na desigualdade de oportunidades educacionais ao fim dos anos 2000 para o caso brasileiro. Já no México, o coeficiente de Gini cresceu consistentemente ao longo do período, revelando a persistente acumulação de recursos que caracteriza os países latino-americanos durante décadas.

A Tabela 1 chama atenção para diferenças nos níveis de gastos educacionais nos dois países. O México aumentou significativamente o investimento público na educação durante o período estudado, passando de $3,6 \%$ do PIB na década de 1980 para $4,9 \%$ nos anos 2000. Em 1992, foram introduzidas reformas educacionais significativas, ${ }^{2}$ incluindo a descentralização do sistema e um

\footnotetext{
${ }^{2}$ Acordo Nacional para a Modernização da Educação Básica.
} 
novo plano de financiamento. Também houve incentivo em direção à avaliação escolar e extensão do número de dias letivos (ZORRILLA, 2002). As duas reformas mais significativas foram a implementação da educação secundária (ensino médio) compulsória em 1993 e uma mudança no currículo em 2006, criando o Sistema Nacional de Bacharelados e a Subsecretaria de Educação Secundária Superior. Essa expansão levou a um crescimento consistente nos gastos educacionais no México. Outra estratégia para aumentar as taxas de matrícula e a conclusão de séries foi a implementação do Progresa/Oportunidades - um programa de transferência de renda condicional focalizado em manter crianças e adolescentes na escola. O impacto desse programa nas taxas de matrícula foi significativo, particularmente na educação secundária de meninas (SCHULTZ, 2000; PARKER, 2003; 2005).

O Brasil, ao contrário, reduziu consideravelmente seus gastos em educação durante os anos 1990 (Tabela 1). O sistema educacional brasileiro teve, historicamente, problemas sistemáticos com baixa cober- tura, altas taxas de repetência, pequeno alcance educacional dos alunos e problemas com acesso à escola (GOMES-NETO; HANUSHEK, 1994; BIRDSALL; SABOT, 1996). Os baixos níveis de alcance educacional foram associados aos altos níveis de fecundidade, problemas econômicos e baixa oferta de escolas (BARROS; LAM, 1996; BIRDSALL; SABOT, 1996). Posteriormente, coortes menores de crianças em idade escolar (LAM; MARTELETO, 2008) e uma menor pressão demográfica (RIANI; RIOSNETO, 2007) influenciaram favoravelmente a matrícula no ensino fundamental. Além disso, novas políticas educacionais desde meados da década de 1990 contribuíram para melhoras recentes da cobertura do sistema educacional brasileiro (VELOSO, 2009). Entretanto, uma grande proporção de adolescentes ainda termina suas carreiras escolares no nível secundário (NÉRI, 2009). Por exemplo, três entre dez adolescentes de 17 a 18 anos não estavam matriculados na escola em 2007.

Um instrumento importante implementado em 2001 é o Bolsa Escola/Família, ${ }^{3}$

TABELA 1

Indicadores sociais, econômicos e educacionais Brasil e México - 1980-2005

\begin{tabular}{|c|c|c|c|c|c|c|c|c|c|c|c|c|}
\hline \multirow[t]{2}{*}{ Países } & \multicolumn{3}{|c|}{ PIB per capita } & \multicolumn{3}{|c|}{ Índice de Gini } & \multicolumn{3}{|c|}{$\begin{array}{l}\text { Gastos públicos na } \\
\text { educação como \% do } \\
\text { PIB }\end{array}$} & \multicolumn{3}{|c|}{$\begin{array}{c}\text { Anos de escolaridade } \\
\text { completos } \\
15-24 \text { anos de idade }\end{array}$} \\
\hline & 1985 & 1995 & 2005 & 1985 (1) & 1995 & 2005 & 1985 & 1995 & 2005 & $1980(1)$ & 1995 (1) & 2005 (1) \\
\hline Brasil & 1.639 & 4.364 & 4.271 & 0,58 & 0,637 & 0,613 & - & 5,0 & 4,0 & 5,5 & 6,5 & 8,8 \\
\hline México & 2.444 & 3.146 & 7.454 & 0,46 & 0,526 & 0,528 & 3,7 & 3,6 & 4,9 & 9,7 & 8,9 & 10,0 \\
\hline
\end{tabular}

(continuação)

\begin{tabular}{|c|c|c|c|c|c|c|c|c|c|}
\hline \multirow{3}{*}{ Países } & \multirow{2}{*}{\multicolumn{3}{|c|}{$\begin{array}{l}\text { Anos de escolaridade completos } \\
25-59 \text { anos de idade }\end{array}$}} & \multicolumn{6}{|c|}{ Matrículas líquidas } \\
\hline & & & & \multicolumn{3}{|c|}{ Ensino fundamental } & \multicolumn{3}{|c|}{ Ensino médio } \\
\hline & 1980 & 1995 & 2005 & 1985 & 1995 & 2005 & 1985 & 1995 & 2005 \\
\hline Brasil & 5,1 & 6,3 & 8,0 & 81,2 & 89,7 & 94,4 & 14,3 & 19,5 & 78,7 \\
\hline México & 8,4 & 8,0 & 9,8 & 99,6 & 100,0 & 97,8 & 45,9 & 51,2 & 67,6 \\
\hline
\end{tabular}

Fonte: World Development Indicators 2008, ECLAC (2008).

(1) Para o Brasil, os dados vêm de tabulações próprias usando dados das PNADs de 1981, 1995 e 2005.

\footnotetext{
3 O PBF (Programa Bolsa Família) faz transferências monetárias para famílias com base em seu nível de renda per capita, número de filhos e idade das crianças, com um limite de transferência proporcional de até três filhos por família. A transferência é feita diretamente para a mãe ou outro beneficiário, preferencialmente do sexo feminino, e tem como condicionalidades a frequência a ao menos $85 \%$ das aulas, vacinação das crianças e algumas outras condições propostas pelo Ministério do Desenvolvimento Social, o gestor do programa.
} 
um programa de transferência de renda condicional similar ao Progresa/Oportunidades no México, com foco na melhoria das matrículas e na frequência e permanência das crianças na escola. Apesar de a matrícula no ensino fundamental no Brasil ser praticamente universal, as matrículas no ensino médio ainda são limitadas. Além disso, estudos recentes mostram que as escolas públicas brasileiras são de menor qualidade do que em outros países da região (CARNOY; GOVE; MARSHALL, 2007).

No Brasil e México, o alcance educacional, medido pelos anos completos de escolaridade, aumentou. A Tabela 1 confirma que as taxas de matrícula no ensino fundamental eram praticamente universais em meados dos anos 2000 tanto no Brasil como no México, enquanto as matrículas na escola secundária ainda são um desafio. As taxas de evasão entre jovens com 14 anos ou mais são altas nos dois países: entre $27 \%$ e $30 \%$ dos adolescentes não frequentam escola, embora as matrículas sejam crescentes (Tabela 1).

Esse quadro se torna ainda mais complexo quando se avalia a qualidade das escolas. Apesar de as melhorias recentes indicarem que o Brasil tem evoluído na cobertura escolar básica, a qualidade da educação pública ainda é um desafio considerável (FRANCO; ALVES; BONAMINO, 2007). Avaliações recentes mostram a dimensão do desafio de equilibrar acesso à escola e qualidade da educação no país. Utilizando dados do Saeb de 1997 a 2005, estudo recente mostra que a piora do desempenho médio dos alunos ao longo do tempo está relacionada à maior presença de estudantes de menor nível socioeconômico, o grupo mais beneficiado pela expansão educacional (RODRIGUES; RIOS-NETO; PINTO, 2011). Simultaneamente, a diferença de desempenho entre alunos mais e menos privilegiados nesse nível de ensino diminuiu (RODRIGUES; RIOS-NETO; PINTO, 2011). Esse tipo de resultado mostra a complexidade do quadro da expansão educacional brasileira, com melhora sistemática dos indicadores de acesso, mas ainda deficitária em relação à qualidade do ensino oferecido às crianças que agora chegam à escola.
Apesar de ambos países terem vivenciado expansões educacionais sem precedentes durante o período aqui examinado, outros países mostraram uma melhoria mais igualitária, como aconteceu no Leste Asiático. $\mathrm{O}$ alcance educacional médio aumentou de maneira significativa no Brasil e no México, mas a dispersão do alcance educacional também elevou-se, o que pode ter como consequência um crescimento da desigualdade no acesso a níveis subsequentes de escolaridade. Pesquisas recentes mostram que a conclusão do ensino médio e a entrada no ensino superior (transições não analisadas neste artigo) formam um gargalo no sistema educacional brasileiro, que conseguiu reduzir as desigualdades de oportunidades educacionais nos níveis mais básicos, mas ainda com desigualdades persistentes nos níveis mais avançados de ensino (RIBEIRO, 2011a; 2011b; MONT'ALVÃO, 2012). Na próxima seção, examinam-se os determinantes da desigualdade de oportunidades educacionais.

\section{Determinantes da desigualdade de oportunidades educacionais: evidências empíricas dos casos brasileiro e mexicano}

Os trabalhos sobre oportunidades e transições educacionais no Brasil apontam para uma melhoria das chances de escolarização de crianças em condições socioeconômicas desfavoráveis nas primeiras transições educacionais, o que ocorreu fundamentalmente a partir da década de 1980. A taxa líquida de escolarização da população entre 7 e 14 anos passou de $86 \%$ para $96 \%$, quando ocorreu praticamente uma universalização da educação básica (SILVA, 2003). Uma situação demográfica mais favorável é uma das razões facilitadoras da intensa expansão educacional brasileira (SILVA; HASENBALG, 2000; LAM; MARTELETO, 2006; 2008; MARTELETO, 2012 no prelo; MARTELETO; SOUZA, 2012 no prelo). Na década de 1990, a população em idade escolar diminuiu em quase um milhão de alunos, reduzindo a demanda agregada por escolaridade.

Além disso, houve também uma diminuição da desigualdade educacional entre 
regiões, grupos de cor, gênero e estratos de renda (SILVA; HASENBALG, 2000). Mudanças institucionais, como aumento do investimento educacional por parte dos Estados, também favoreceram a realização educacional ao longo das coortes (RIBEIRO, 2011a; 2011b). A decomposição de efeitos de idade, período e coorte para meninas que realizaram a transição para a quinta série entre 1982 e 2008 mostra um forte efeito para as coortes expostas à transição para essa série na década de 1980, sugerindo que os resultados positivos dos anos 1990 tiveram origem em investimentos educacionais feitos no decênio anterior (GUIMARÃES; RIOS-NETO, 2011).

No México a situação é semelhante, embora o cenário de expansão educacional do nível fundamental tenha se consolidado já em meados do século passado. Entre as décadas de 1950 e 1970, o número de alunos inscritos no ensino primário aumentou de 3 para 9 milhões de estudantes, e a matrícula no ensino secundário passou de apenas 70 mil jovens para aproximadamente um milhão (MIER; ROCHA; ROMERO, 2002; RIZO, 2002; ZORILLA, 2004). O país passou por uma expansão da escolarização e uma relativa, ainda que desigual, melhoria no desempenho educacional de sua população. A escolaridade média aumentou e a desigualdade de oportunidade educacional entre jovens das diferentes unidades federativas diminuiu (RIZO, 2002). Essa expansão, como no Brasil, também ocorreu em épocas de crescimento econômico. A posterior estabilização do crescimento populacional em decorrência da transição demográfica fez com que a pressão no sistema educacional, do ponto de vista da demanda dos alunos, se estabilizasse como consequência da desaceleração do crescimento das coortes mais jovens (SAUCEDO et al., 2010).

Um aspecto importante no caso mexicano é a atratividade da imigração para os
Estados Unidos e seus efeitos no alcance educacional das crianças, que podem tanto se beneficiar com os recursos enviados por familiares que migraram como serem desfavorecidos pela possibilidade de migração atraente do ponto de vista da mobilidade social, mas que muitas vezes representa o encerramento da carreira educacional (SAUCEDO et al., 2010). ${ }^{4}$

Os trabalhos focados especificamente na avaliação de transições educacionais - examinando coortes mais velhas - indicam uma redução das desigualdades de oportunidades nas primeiras transições educacionais, mas uma persistência da desigualdade nas transições mais avançadas, tanto no Brasil quanto no México (RIZO, 2002; RIBEIRO, 2007; 2011a; 2011b; MONT'ALVÃO, 2012). Uma série de estudos recentes confirma a continuidade da melhoria nos resultados educacionais para coortes nascidas entre 1932 e 1979 ou 1944 e 1983 (RIBEIRO, 2011a; 2011b), para o caso do Brasil, e para jovens de 12 a 14 anos nos censos de 1960, 1970, 1980, 1990 e 2000, para o México (MIER et al., 2002). Esses trabalhos mostram um aumento do percentual de crianças fazendo as primeiras transições educacionais condicionais; ou seja, ao longo do tempo, um número cada vez maior completou a primeira transição (quatro anos de escolaridade), e das que completaram a primeira transição, um número cada vez maior completou a segunda transição (oito anos de escolaridade), que seria a conclusão do ensino fundamental (RIBEIRO, 2011a; 2011b).

Ao se avaliarem os fatores relacionados às mudanças ocorridas nas transições educacionais entre 1981 e 1999 no Brasil, Silva (2003) observa uma redução das desvantagens associadas à residência urbana, renda familiar e raça nas chances de transições condicionais para quarta e oitava séries. Ao mesmo tempo, houve

\footnotetext{
${ }^{4}$ Destaca-se também a presença de características adscritas tanto no contexto mexicano como no brasileiro. Infelizmente, a caracterização das desigualdades de oportunidades a partir de etnia e raça, importantes para a estruturação da desigualdade mexicana e brasileira, não poderá ser feita no âmbito do presente artigo pela dificuldade de comparar esses dados e pela limitação dos dados. No entanto, reconhecemos a importância de tais características e por isso a elas nos referimos nessa revisão dos trabalhos que nos precedem.
} 
um aumento nas chances de transições condicionais para quarta e oitava séries para meninas vis-à-vis meninos. Ribeiro (2011b), ao analisar as transições educacionais de indivíduos entre 15 e 64 anos utilizando dados de 1996-1997 da Pesquisa de Padrões de Vida (PPV), também demonstra a recente vantagem educacional das mulheres sobre os homens ao longo das coortes e a diminuição das vantagens educacionais associadas às áreas urbanas. As desigualdades raciais, apesar de ainda estarem presentes, também diminuíram, apresentando maior convergência entre os níveis educacionais dos grupos de cor (SILVA, 2003; MARTELETO, 2012).

Recentemente, alguns estudos passaram a destacar a importância da rede de ensino (privada ou pública) para a estruturação da desigualdade de oportunidades educacionais no Brasil. Ribeiro (2011a) sugere que alunos vindos de escolas particulares têm sete vezes mais chances de completar o ensino fundamental. Essa é uma dimensão importante e será avaliada posteriormente. ${ }^{5}$ Outro estudo recente mostra que a rede privada é mais desigual do que a pública, tanto para a conclusão do ensino médio como para a transição para o ensino superior, uma vez que os efeitos de origens sociais, raça, gênero e região são mais fracos para a rede pública do que para a privada. No entanto, entre 2001 e 2007, houve crescimento dos efeitos dessas variáveis na escola pública (MONT'ALVÃO, 2012, p. 429).

Utilizando dados para indivíduos e municípios do Censo 2000 e dados escolares do Censo Escolar 2000, Riani e Rios-Neto (2011) apontam que a qualificação do corpo docente dilui o efeito negativo da baixa escolaridade materna na probabilidade de atraso escolar no ensino fundamental. A nucleação e a restrição de oferta escolar também constituem fatores relevantes no ensino médio (RIANI; RIOS-NETO, 2008).

Entre as décadas de 1950 e 2000, o México também apresenta melhorias signi- ficativas em seus resultados educacionais. A desigualdade de gênero em favor dos meninos, presente em todos os níveis educacionais em meados do século XX, desapareceu ou foi invertida, dando lugar a um gap em favor das meninas para a conclusão dos quatro primeiros anos do ensino básico. Diferente do caso brasileiro, a desigualdade de gênero em favor das meninas mexicanas é invertida após a conclusão dos quatro primeiros anos de escolaridade. No México, o investimento familiar na educação dos meninos tem sido historicamente superior ao das meninas, sobretudo nos estágios mais avançados do sistema educacional (MIER; ROCHA; ROMERO, 2002), tendência que vem mudando, mas ainda permanece.

Como o Brasil, o México é marcado por uma heterogeneidade regional dos resultados educacionais, havendo grande desvantagem nas áreas rurais, o que já não é mais tão saliente no Brasil. As diferenças entre municípios em regiões rurais e urbanas também diminuíram, apesar de ainda estarem presentes, assim como as desvantagens dos grupos indígenas, que se reduziram significativamente, mas apenas para o nível básico (MIER; ROCHA; ROMERO, 2002). As desigualdades educacionais relativas aos que falavam línguas indígenas também decresceram (MIER; ROCHA; ROMERO, 2002, p. 67). No caso mexicano, a escolaridade do chefe do domicílio, as características domiciliares que refletem o bem-estar (tipo de piso, presença de saneamento) e o número de irmãos são variáveis decisivas para a transição educacional avaliada (MIER; ROCHA; ROMERO, 2002, p. 81).

\section{Determinantes da desigualdade de oportunidades educacionais: estudos teóricos}

Os estudos teóricos sobre os resultados educacionais apontam forças macroestruturais, assim como fatores escolares e familiares como determinantes importantes

\footnotetext{
${ }^{5}$ A riqueza dos pais em termos de ativos e bens contribui para explicar as chances de fazer com sucesso todas as transições educacionais, o que aponta para a relevância desse tipo de recurso na estruturação das desigualdades educacionais, como era de se esperar (TORCHE; RIBEIRO, 2012).
} 
dos resultados educacionais (BUCHMANN; HANNUM, 2001). Entre os primeiros, o Estado e as condições macroeconômicas têm papéis centrais porque podem afetar tanto a oferta quanto a demanda por educação (HANNUM; BUCHMANN, 2005). Com a crise econômica e os consequentes ajustes estruturais, governos têm menos recursos para gastar na educação, com implicações negativas para a garantia da qualidade do ensino. Condições macroeconômicas têm tido um impacto importante na América Latina devido às condições voláteis que a região vivenciou, como a crise econômica dos anos 1980, que afetou Brasil e México de forma igualmente intensa.

O efeito de condições macroeconômicas desfavoráveis nos investimentos das famílias na educação não é claro, e pode resultar em maiores ou menores investimentos na escolaridade das crianças. De acordo com a ideia de efeitos de renda (income effects), famílias tirariam os filhos da escola para lidar com condições negativas impostas por crises macroeconômicas, já que a manutenção dos investimentos em educação reduz a renda familiar no curto prazo. Isso é particularmente relevante para os contextos brasileiro e mexicano, em que o trabalho de adolescentes em mercados informais é uma estratégia de sobrevivência para muitas famílias (ORAZEM; SEDLACEK; TZANNATOS, 2009).

A crise econômica da década de 1980 foi associada a uma participação crescente de crianças e adolescentes brasileiros no mercado de trabalho e piores resultados educacionais (DURYEA; LAM; LEVISON, 2007). Do outro lado do espectro, se famílias agem de acordo com a ideia de efeitos de substituição (substitution effects), seria mais provável que adolescentes progredissem na escola em taxas maiores durante a crise econômica, porque as altas taxas de desemprego reduzem o custo de oportunidade educacional. Assim, as famílias substituiriam a renda de curto prazo advinda do emprego dos adolescentes em prol dos retornos educacionais de longo prazo, que provavelmente viriam de um maior investimento escolar ao longo do ciclo de vida (TORCHE, 2010).

Entre os fatores familiares associados ao alcance educacional, características da origem familiar, especialmente o nível de escolaridade dos pais, são importantes fatores preditores do alcance educacional das crianças tanto no Brasil como no México (BARROS; LAM, 1996; BINDER, 1998; BINDER; WOODRUFF, 2002; GIORGULISAUCEDO, 2002; RIBEIRO, 2007). Entretanto, o que é menos claro é o quanto as desvantagens educacionais associadas à origem social familiar mudaram para coortes de adolescentes das décadas de 1980, 1990 e 2000 como um resultado da expansão educacional e das melhorias macroeconômicas dos anos 2000.

Diferentes teorias tentam explicar como a expansão educacional pode influenciar o efeito da origem social no alcance educacional. A teoria da modernização assume que, com a industrialização e o crescimento da demanda por trabalho qualificado, a expansão educacional invariavelmente reduziria a influência da origem social no alcance educacional (TREIMAN, 1970). Contudo, um grande número de trabalhos demonstrou que a expansão educacional sozinha não reduz as chances relativas que pessoas com uma origem social privilegiada têm em relação àquelas com origem social desprivilegiada (SHAVIT; BLOSSFELD, 1993; TORCHE, 2010). A teoria da reprodução social (BOURDIEU; PASSERON, 1977) propõe que o sistema educacional reproduz as desigualdades presentes na sociedade. Portanto, estudantes que vêm de contextos desprivilegiados também se encontram em desvantagem no sistema educacional, o que resulta em uma desigualdade de oportunidades. Desse ponto de vista teórico, a expansão educacional aumentaria por meio do acesso de estudantes de baixo status socioeconômico nos níveis iniciais da escolarização, mas a desigualdade continuaria nos níveis educacionais mais altos.

Raftery e Hout (1993) argumentam que o processo de desigualdade maximamente mantida (maximally maintained inequality MMI) explica a persistência da desigualdade educacional. Para os autores, a desigualdade diminui como consequência da expansão educacional somente quando países atingem a universalização de determinado nível de ensino. A MMI propõe que estudantes em 
desvantagem atingem gradualmente maiores níveis de realização educacional, mas que o enfraquecimento da associação entre origem social e a escolaridade depende da saturação de níveis educacionais entre as classes privilegiadas. Essa tese ajudaria a explicar os gargalos que sistemas educacionais de alguns países enfrentam nos níveis mais avançados do sistema educacional, por exemplo.

Finalmente, segundo a perspectiva da desigualdade efetivamente mantida (effecively maintained inequality - EMI), mesmo que a expansão educacional leve a maiores níveis de alcance educacional, outras dimensões presentes dentro da estrutura social contribuem para a manutenção das desigualdades educacionais (LUCAS, 2001). Essa perspectiva destaca a importância de medidas da qualidade das escolas e outros fatores como o nível de prestígio do curso estudado e o setor da escola (pública ou privada), aspectos que funcionariam para estruturar e manter diferentes chances de sucesso educacional e posteriores oportunidades de trabalho. É examinado se a qualidade da educação na estratificação educacional de adolescentes em idade apta a cursar a escola secundária é particularmente importante no contexto de países como Brasil e México, onde a matrícula na educação secundária atingiu níveis satisfatórios somente muito recentemente.

Com base nos estudos empíricos sobre o tema e nas perspectivas teóricas discutidas anteriormente, este artigo oferece as seguintes hipóteses:

- matrícula escolar: as desvantagens na matrícula dos adolescentes associadas à origem social eram menores na década de 1980 do que nos anos 1990 e 2000 porque as famílias não estavam tirando os filhos da escola durante a crise econômica, o que sinalizaria um efeito substituição. Por outro lado, se os resultados indicarem que as associações entre origem social familiar e frequência escolar dos adolescentes eram maiores nos anos 1980 do que nos 1990 e 2000 , seriam encontrados subsídios para a noção de que as famílias agiram de acordo com um efeito renda;

- transições educacionais:

- ensino fundamental: tem-se como hipótese que as associações entre origem social e probabilidade de os adolescentes terminarem o ensino fundamental diminuíram ao longo do período examinado tanto para o Brasil quanto para o México;

- educação secundária: a hipótese é de que a associação entre origem social e chances de os adolescentes fazerem as transições para a escola secundária diminuiu ao longo do período analisado. Em contraste com o ensino fundamental, esperase que a magnitude desse declínio varie entre Brasil e México de acordo com o estágio da expansão educacional do país, sendo menor para o México, onde a universalização do ensino fundamental ocorreu anteriormente ao Brasil. Resultados nessa direção seriam evidências para a perspectiva $\mathrm{MMl}$;

- setor: a hipótese é de que a associação entre origem social e matrícula no ensino particular aumentou ao longo do período estudado, o que sugeriria um fortalecimento de novos níveis de diferenciação no sistema educacional. A medida que a expansão educacional e as matrículas no ensino secundário crescem, a configuração das estruturas sociais proporciona uma manutenção dos privilégios ligados ao alto status socioeconômico, principalmente por meio do acesso ao ensino privado (EMI).

\section{Dados e metodologia}

No presente estudo, foram utilizados dados de pesquisas domiciliares nacionalmente representativas para os dois países analisados. Para o Brasil, empregaram-se dados de 1982, 1992 e 2007 das PNADs (Pesquisa Nacional por Amostra de Domicílio), cuja amostragem segue um pro- 
cedimento probabilístico de três estágios baseado primeiramente em municípios, posteriormente em setores censitários dentro desses municípios e finalmente em domicílios nos limites do setor censitário. Para o México, utilizaram-se dados domiciliares nacionalmente representativos para os anos de 1984, 1992 e 2008, da pesquisa ENIGH (Encuesta Nacional de Ingresos y Gastos de los Hogares). Os dados da PNAD e ENIGH são altamente comparáveis.

A amostra deste estudo consiste em jovens entre 15 e 18 anos que, teoricamente, estão em uma idade em que deveriam ter completado o ensino fundamental e feito a transição para a educação secundária. Em termos práticos, os dados utilizados são de pesquisas domiciliares e, portanto, não há informação sobre escolaridade dos pais para adolescentes que já saíram de casa. ${ }^{6}$ A escolaridade dos pais é um dos determinantes mais importantes da escolaridade de crianças e adolescentes ${ }^{7}$ e a maioria dos jovens entre 15 e 18 anos vive com ao menos um dos pais em seu domicílio. ${ }^{8}$ Para incluir a escolaridade materna na análise, restringiu-se a amostra a filhos do chefe do domicílio e com a mãe presente. ${ }^{9}$ Foram testadas diferenças entre nossa amostra e amostras de adolescentes que não viviam com suas mães, além de amostras de adolescentes que não são filhos do chefe do domicílio e não se verificaram diferenças significativas entre os grupos. Ressalta-se a importância de se certificar a não existência de diferenças significativas entre as amostras quando essa estratégia é utilizada. Quando aumentada a idade dos jovens, por exemplo, aí sim passam a existir diferenças significativas entre as amostras, tornando os resultados enviesados.

Essa estratégia impõe algumas limitações, que serão discutidas nas seções a seguir. No entanto, tal estratégia analítica para estudar a estratificação educacional usando adolescentes é necessária para lidar com a inexistência de dados que cubram um período extenso e que, ao mesmo tempo, contenham informação da origem social familiar. Essa abordagem, mesmo com suas limitações, tem a vantagem significativa de não depender de informações retrospectivas fornecidas pelo entrevistado, ou seja, ao seguir essa estratégia minimizam-se de forma significativa possíveis vieses de mensuração comuns em dados retrospectivos. Além disso, a estratégia adotada no presente artigo pode ser replicada para gerar evidências sobre a estruturação das desigualdades educacionais em países com limitações de dados semelhantes, mas onde é possível encontrar informações disponíveis em pesquisas domiciliares e censos.

Utilizou-se a escolaridade da mãe como uma medida de origem social familiar por dois motivos. Primeiramente, a escolaridade materna afeta as crianças além dos benefícios tradicionais associados ao capital econômico. A alta escolaridade materna contribui para que as habilidades cognitivas dos filhos aumentem, já que essas mães têm mais conhecimentos sobre o que é

\footnotetext{
6 Exceções são as PNADs de 1982 e 1996, que têm módulos especiais sobre a origem social dos entrevistados, com o objetivo de avaliar sua mobilidade social.

${ }^{7}$ Apesar de sua importância para o estudo de transições educacionais, não foi incluído o status ocupacional do pai em nossos modelos por quatro razões. Primeiramente, os códigos da ocupação do pai para os dados dos anos 1980 no México não são suficientemente detalhados de forma a possibilitar conversões para a classificação ocupacional ISEI, que possibilitaria sua comparação com os dados brasileiros. Segundo, houve diversas mudanças nas classificações ocupacionais em ambos países, o que impossibilita a comparação ao longo do tempo intrapaíses, bem como entre países pela falta de tabelas de conversão código a código. Terceiro, devido ao fato de utilizarmos dados domiciliares, para incluir a ocupação do pai em nossos modelos teríamos que considerar apenas os dados sobre adolescentes que vivem com seus pais, o que limitaria de forma mais severa as amostras do que a estratégia implementada, ao utilizar domicílios com a mãe presente. Por fim, para os anos em que a implementação da estratégia era possível, incluímos a ocupação do pai nos modelos e os resultados não variaram de forma significativa em relação aos encontrados.

8 Para o Brasil, 84,3\% dos jovens entre 15 e 18 anos eram filhos do chefe do domicílio em 1982, 82,6\% em 1992 e $82,2 \%$ em 2007. No México, essas proporções correspondiam a 84,5\% em 1984, 83,1\% em 1992 e 83,8\% em 2008.

9 Diversos pesquisadores utilizaram dados domiciliares para examinar vários fatores relacionados a crianças e adolescentes no Brasil, México e América Latina em geral, empregando estratégia semelhante (BARROS; LAM, 1996; BEHRMAN; SZÉKELY, 2001; FILGUEIRA; FILGUEIRA; FUENTES, 2003; MARTELETO, 2012).
} 
necessário para que as crianças sejam bem-sucedidas (AUGUSTINE; CAVANAGH; CROSNOE, 2009). Além disso, como discutido anteriormente, devido à natureza das informações domiciliares, dispõe-se de informações da origem social familiar somente para adolescentes que vivem com ao menos um dos pais. Tendo em vista que a maior parcela desses jovens vive com suas mães do que com seus pais, ao se usar a escolaridade materna é possível cobrir uma maior proporção de adolescentes em nossa análise.

Foram utilizadas simples regressões logísticas para examinar as matrículas escolares, conclusão do ensino fundamental, entrada na escola secundária ${ }^{10}$ e matrícula em escola particular para os anos 1980 , 1990 e 2000 em cada país. Esses modelos são amplamente empregados para analisar desigualdades de oportunidades educacionais e oferecem uma estratégia mais flexível e menos paramétrica para capturar a realização educacional. A equação que representa o modelo é:

$$
\operatorname{Pr}(Y=1 \mid X)=\Phi\left(X^{\prime} \beta\right),
$$

onde Pr denota a probabilidade de terminar o ensino fundamental ou fazer a transição para o ensino secundário e $X$ é um vetor de covariáveis que descreveremos adiante.

Em todos os modelos foram utilizados, como controles, sexo, idade, escolaridade da mãe, estrutura do domicilio, log da renda domiciliar per capita e urbanização. ${ }^{11}$ Também foi feito o controle pelas regiões de residência no Brasil e no México - as cinco principais regiões brasileiras e as sete principais regiões mexicanas.

Reportamos erros-padrão robustos que corrigem o agrupamento de múltiplos adolescentes na mesma família. Uma vez que esperamos que as desigualdades de oportunidades educacionais associadas à origem social dos adolescentes tenham mudado ao longo do tempo, estimamos os modelos separadamente para cada ano. Posteriormente, testamos se as diferenças entre os coeficientes são estatisticamente significativas em modelos aplicados a amostras agrupadas, no qual interagimos as variáveis avaliadas com o ano da pesquisa.

\section{Resultados}

O Gráfico 1 mostra a evolução da frequência escolar dos jovens entre 15 e 18 anos durante as décadas de 1970, 1980, 1990 e 2000. Para o Brasil, observou-se uma evolução monotônica na proporção de jovens frequentando a escola a partir dos anos 1990. O México, por sua vez, também apresentou resultados positivos ao final do período avaliado, mas com aumentos significativos apenas a partir dos anos 2000 . O que chama atenção, além do intervalo que separa os dois países e que indica meIhores resultados para o Brasil, é que ainda existe uma grande proporção de jovens fora da escola. Como essa é uma idade em que os adolescentes ainda deveriam estar completando seu período de escolarização para concluir ao menos o ensino médio, o Gráfico 1 demonstra claramente que, apesar dos resultados positivos conseguidos nos últimos anos nos dois países, ainda há um grande esforço a ser feito.

O Gráfico 2 traz um indicador mais específico: a proporção de jovens entre 15 e 18 anos que completaram o ensino fundamental. Como a literatura aponta, o México acelerou os investimentos nesse

\footnotetext{
10 É importante notar que Brasil e México organizam seus sistemas educacionais de forma diferente. No Brasil, o ensino fundamental dura oito anos (a duração do ensino fundamental no Brasil passou a ser de nove anos; não afetando nosso estudo), enquanto no México ele dura seis. Por razões comparativas, examinamos a conclusão do fundamental e a transição para o ensino médio dado que o ciclo anterior foi completado. Isso significa que, no caso brasileiro, analisamos as transições para o ensino médio (primeira série do ensino médio ou segundo grau), dado que o ensino fundamental (a oitava série do ensino fundamental) foi completado. Também para o México examinamos as transições entre os ensinos fundamental e médio, mas não há uma comparação perfeita entre os dois sistemas. Naquele país, a transição se dá um ano mais tarde do que no Brasil. Optamos por analisar essa transição porque ela está mais sujeita a desistências.

11 Resultados de testes de colinearidade indicam que os modelos estimados não têm problemas com multicolinearidade. As estatísticas de inflação de variância dos fatores (variance inflation factors ou VIF) ficam perto de 1.
} 


\section{GRÁFICO 1}

Matrículas escolares de adolescentes de 15 a 18 anos

Brasil e México - 1976-2009

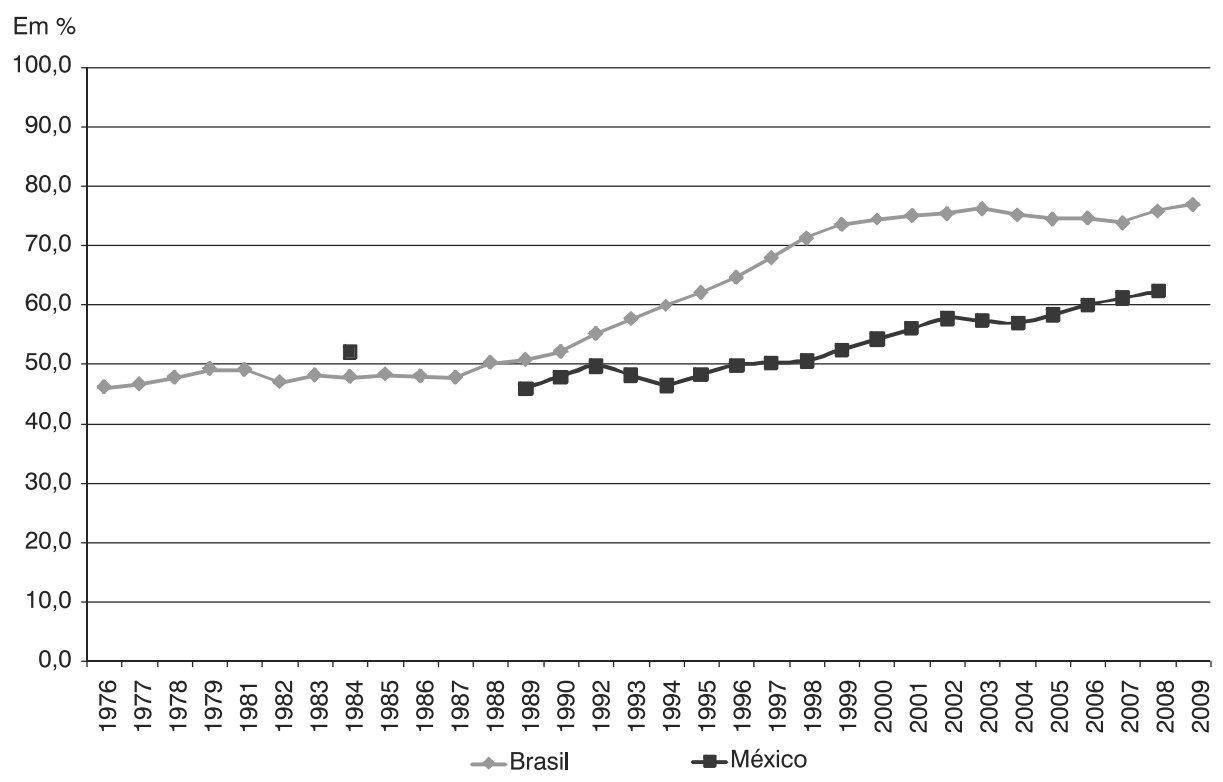

Fonte: IBGE. PNAD; ENIGH.

Nota: Para os anos sem dados, usamos médias entre dois pontos disponíveis. Os anos de 1994 e 2000 são médias para o Brasil. Os anos de 1990, 1993, 1995, 1997, 1999, 2001 e 2003 são médias para o México.

GRÁFICO 2

Proporção de adolescentes de 15 a 18 anos completando o ensino fundamental Brasil e México - 1976-2009

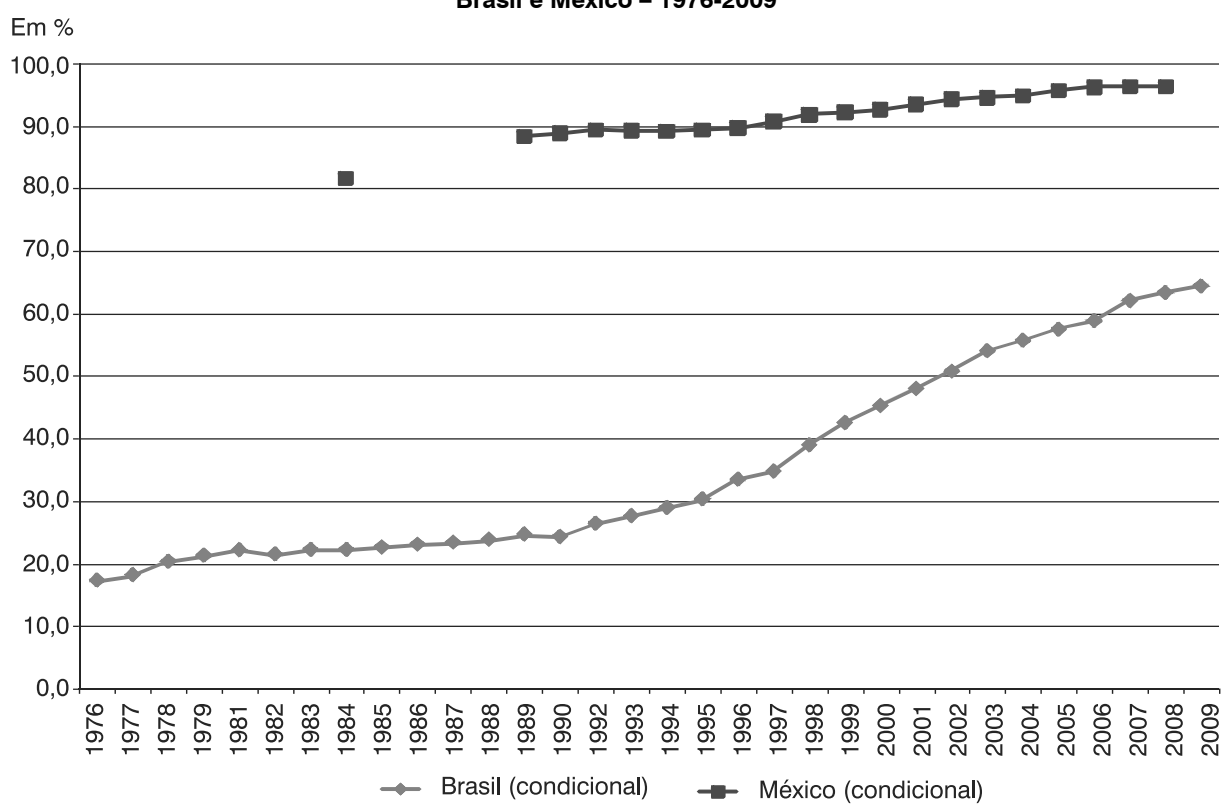

Fonte: IBGE. PNAD; ENIGH.

Nota: Para os anos sem dados, usamos médias entre dois pontos disponíveis. Os anos de 1994 e 2000 são médias para o Brasil. Os anos de 1990, 1993, 1995, 1997, 1999, 2001 e 2003 são médias para o México. 
nível de ensino antes do Brasil, o que se reflete nas altas taxas de conclusão do nível fundamental no México, praticamente sua universalização, já no início dos anos 2000. O Brasil, por sua vez, teve uma aceleração da expansão mais tardia e ainda apresenta proporções mais baixas de jovens de 15 a 18 anos com o ensino fundamental completo. Somente na década de 1990 passa-se a observar uma tendência praticamente linear de crescimento no Brasil. O Gráfico 3 mostra as transições para o ensino médio, tanto condicionais como incondicionais à conclusão do ensino fundamental. Ambos países apresentam um aumento da proporção de adolescentes chegando ao ensino médio.

A escolaridade média dos jovens de 15 a 18 anos, entre 1976 e 2009, é apresentada no Gráfico 4. Essa medida é uma espécie de síntese das tendências avaliadas nos gráficos anteriores. Percebe-se que a velocidade do aumento da escolaridade foi mais rápida no Brasil do que no México, embora a escolaridade média de jovens em meados dos anos 1980 seja dois anos mais alta no México em relação ao Brasil. A diferença na escolaridade média dos jovens entre os dois países diminuiu consideravelmente nos anos 2000, apesar de ainda haver uma diferença em favor do México. Nota-se que isso não significa que a performance brasileira foi superior à mexicana. Como já mencionado, os melhores resultados brasileiros se apresentam no nível educacional em que o México já havia feito consideráveis investimentos.

As médias e proporções das amostras utilizadas por ano e por país são apresentadas na Tabela 2. Mais de $60 \%$ dos adolescentes em ambos países viviam em áreas urbanas já na década de 1980. A proporção vivendo em áreas urbanas era particularmente alta para o Brasil. No México, cerca de $20 \%$ dos jovens entre 15 e 18 anos residiam em áreas rurais nos anos 2000 . O nível de escolaridade materno cresceu significativamente em ambos países ao longo das últimas três décadas, com Mé-

GRÁFICO 3

Transição para o ensino médio de adolescentes de 15 a 18 anos

Brasil e México - 1976-2009

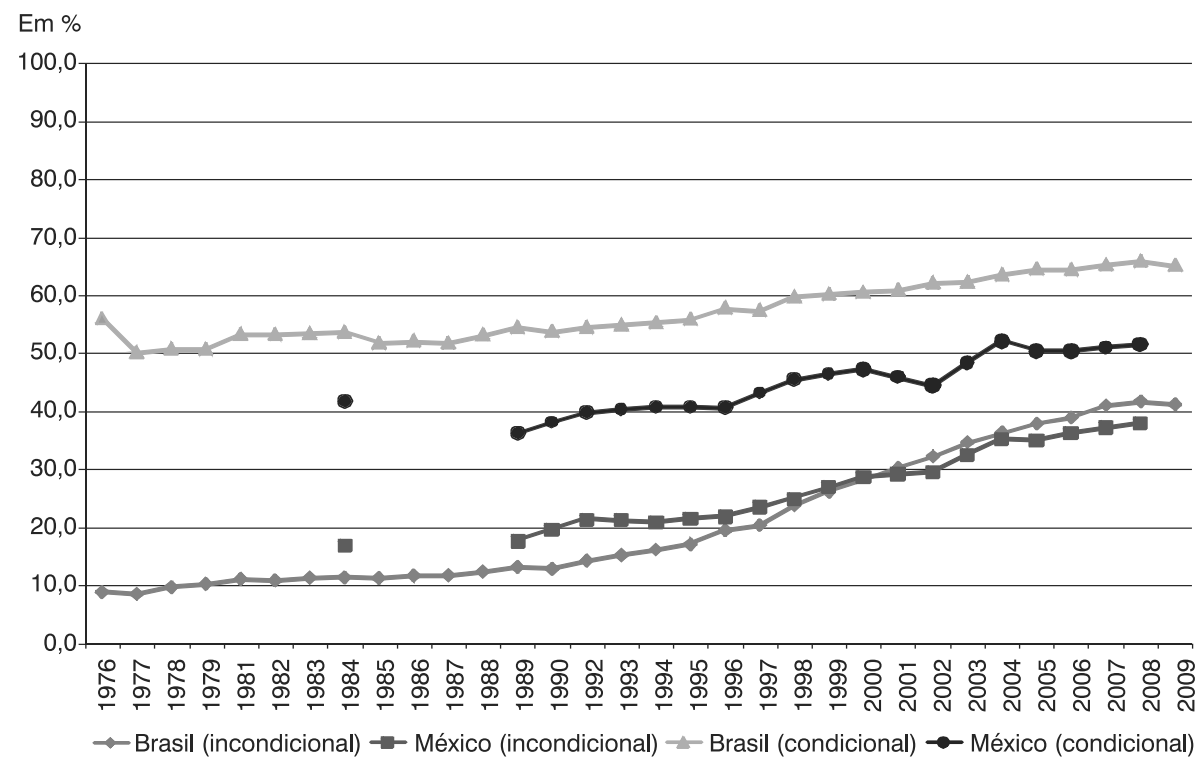

Fonte: IBGE. PNAD; ENIGH.

Nota: Para os anos sem dados, usamos médias entre dois pontos disponíveis. Os anos de 1994 e 2000 são médias para o Brasil. Os anos de 1990, 1993, 1995, 1997, 1999, 2001 e 2003 são médias para o México. 


\section{GRÁFICO 4}

Anos de escolaridade de adolescentes de 15 a 18 Anos

Brasil e México - 1976-2009

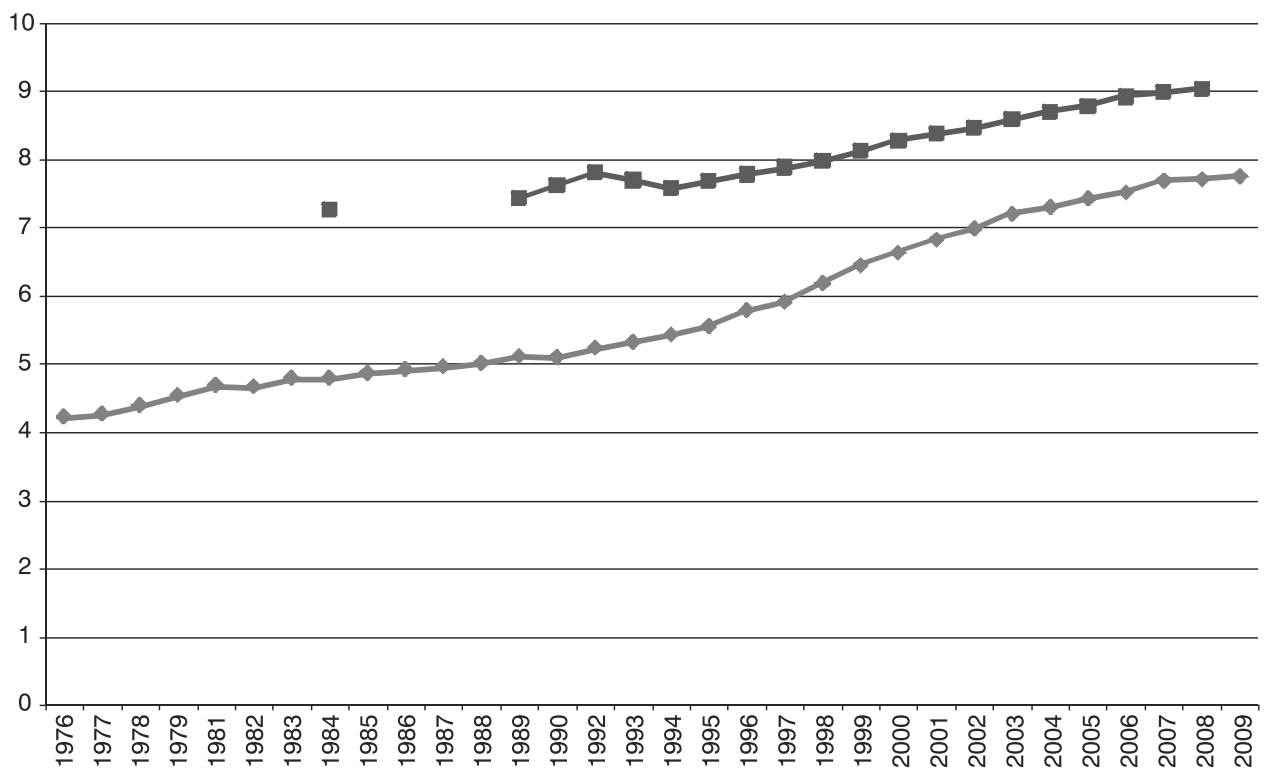

$\leadsto$ Brasil $\quad-$-México

Fonte: IBGE. PNAD; ENIGH.

Nota: Para os anos sem dados, usamos médias entre dois pontos disponíveis. Os anos de 1994 e 2000 são médias para o Brasil. Os anos de 1990, 1993, 1995, 1997, 1999, 2001 e 2003 são médias para o México.

xico e Brasil tendo um nível de escolaridade semelhante ao final dos anos 2000 (Tabela 2). Outra mudança relevante, particularmente entre a década de 1990 e o fim dos anos 2000, é o aumento na proporção de adolescentes vivendo em famílias chefiadas por mulheres. Se durante a década de 1980 uma proporção relativamente baixa de adolescentes vivia em domicílios chefiados por mulheres $(13,86 \%$ para o Brasil e $11,41 \%$ para o México), em fins dos anos 2000 essa parcela cresceu significativamente $(28,9 \%$ no Brasil e $20,99 \%$ no México).

A Tabela 3 mostra, para cada covariável utilizada, a proporção de adolescentes matriculados na escola, que completaram o ensino fundamental, que fizeram a transição para o ensino médio e os matriculados em escola particular. As estudantes do sexo feminino tiveram uma vantagem crescente na conclusão do ensino fundamental no Brasil, em relação àqueles do sexo masculino. Isso não ocorreu no México. Se encontram também em vantagem adolescentes em áreas urbanas. Nos dois países, adolescentes cujas mães possuem alta escolaridade tinham uma grande vantagem em comparação àqueles com mães com nenhuma ou baixa escolaridade formal. Com poucas exceções, os padrões gerais para a probabilidade de transição para o ensino médio são similares a esses resultados.

Os coeficientes das regressões calculadas para a probabilidade de matrícula escolar encontram-se na Tabela 4. As variáveis de controle têm os sinais esperados: crianças mais velhas e aquelas em domicílios de renda mais baixa possuem probabilidade menor de matrícula na escola. Um resultado interessante é que meninas têm probabilidades maiores de estarem ma- 
triculadas na escola nos dois países e anos avaliados; mas a magnitude do coeficiente aumentou ao longo do tempo, o que sugere uma crescente desigualdade de gênero na matrícula escolar em favor das meninas nos dois países $(0,208$ para o Brasil e 0,109 para o México). Esse padrão é esperado e foi documentado recentemente para outros países (GRANT; BEHRMAN, 2010).

Verifica-se um sensível aumento das desvantagens na matrícula escolar associadas à origem familiar entre 1980 e 1990 no México. No Brasil há um pequeno, mas estatisticamente insignificante, declínio na associação entre as décadas de 1980 e 1990 (Tabela 4). Os resultados apresentados sugerem que famílias de baixo status socioeconômico provavelmente tiraram seus filhos da escola no México durante a crise dos anos 1980, indicando que um efeito renda possa ter operado nesses domicílios durante essa década. Os anos 2000 oferecem uma história diferente.
Os dados da Tabela 4 também demonstram declínio significativo do papel da origem social na probabilidade de matrícula escolar no Brasil e no México, a partir da década de 1990. A diferença entre os coeficientes dos anos 1990 e 2000 é estatisticamente significante para Brasil e México $(p<0,01)$. Para ilustrar de forma clara o que isso representa, o Gráfico 5 mostra, por exemplo, que na década de 1980 adolescentes que tinham mães com ensino superior possuíam uma vantagem de $59 \%$ na probabilidade de matrícula escolar em relação àqueles com mães sem educação formal. Esse diferencial se reduziu para $18 \%$ nos anos 2000 . No México, por sua vez, o efeito da origem na probabilidade de conclusão desse nível de ensino se mantém estável. As probabilidades de matrícula preditas foram calculadas com todas variáveis em suas médias para cada nível de escolaridade materno nas décadas de 1980, 1990 e 2000 para cada país.

TABELA 2

Médias e proporções amostrais de adolescentes de 15 a 18 anos, filhos do chefe do domicílio, segundo variáveis selecionadas

Brasil e México - 1982-2008

\begin{tabular}{lrrrrrrr}
\hline Variáveis selecionadas & \multicolumn{3}{c}{ Brasil } & & \multicolumn{3}{c}{ México } \\
\cline { 2 - 3 } \cline { 5 - 7 } & 1982 & 1992 & 2007 & & 1984 & 1992 & 2008 \\
\hline Mulher (\%) & 46,14 & 45,67 & 45,75 & 46,49 & 48,85 & 47,02 \\
Idade (anos) & 16,44 & 16,39 & 16,45 & 16,41 & 16,46 & 16,44 \\
$\quad$ Desvio-padrão & $(1,11)$ & $(1,11)$ & $(1,12)$ & $(1,14)$ & $(1,12)$ & $(1,12)$ \\
Área urbana (\%) & 69,47 & 75,96 & 81,01 & 62,66 & 74,63 & 74,85 \\
Escolaridade da mãe (\%) & & & & & & \\
$\quad$ Sem escolaridade formal & 37,39 & 28,77 & 6,70 & 24,44 & 21,98 & 10,23 \\
$\quad$ Ensino fundamental (algum ano feito ou ensino & 57,44 & 59,65 & 58,73 & 66,87 & 60,14 & 43,09 \\
$\quad$ fundamental completo) & 3,61 & 7,46 & 23,41 & 6,81 & 15,70 & 38,10 \\
$\quad$ Ensino médio (algum ano feito ou ensino médio completo) & 1,56 & 4,12 & 11,16 & 1,88 & 2,18 & 8,58 \\
$\quad$ Ensino superior (algum ano feito ou superior completo) & 2,64 & 3,75 & 7,02 & 3,80 & 4,39 & 7,06 \\
Média da escolaridade da mãe (em anos) & $(3,04)$ & $(3,83)$ & $(4,32)$ & $(3,11)$ & $(3,67)$ & $(4,42)$ \\
$\quad$ Desvio-padrão & 13,86 & 17,03 & 28,29 & 11,41 & 10,67 & 20,99 \\
Domicílios chefiados por mulheres (\%) & 9,14 & 12,65 & 5,54 & 10,05 & 13,72 & 8,62 \\
Log da renda per capita domiciliar & $(0,98)$ & $(1,06)$ & $(0,99)$ & $(0,83)$ & $(0,86)$ & $(0,82)$ \\
$\quad$ Desvio-padrão & 37.894 & 21.116 & 23.186 & 1.926 & 4.088 & 8.547 \\
N. abs. & & & & &
\end{tabular}

Fonte: IBGE. PNAD 1982, 1992 e 2007; ENIGH 1984, 1992 e 2008. 
TABELA 3

Transições educacionais para adolescentes entre 15 e 18 anos, segundo variáveis selecionadas Brasil e México - 1982-2007

\begin{tabular}{|c|c|c|c|c|c|c|c|c|c|c|c|}
\hline \multirow{4}{*}{ Variáveis selecionadas } & \multicolumn{11}{|c|}{ Em porcentagem } \\
\hline & \multicolumn{3}{|c|}{ Matrícula escolar } & \multicolumn{3}{|c|}{$\begin{array}{l}\text { Completar o ensino } \\
\text { fundamental }\end{array}$} & \multicolumn{3}{|c|}{$\begin{array}{l}\text { Transição para o } \\
\text { ensino médio }\end{array}$} & \multicolumn{2}{|c|}{$\begin{array}{l}\text { Matrícula em } \\
\text { escola privada }\end{array}$} \\
\hline & \multicolumn{11}{|c|}{ Brasil } \\
\hline & 1982 & 1992 & 2007 & 1982 & 1992 & 2007 & 1982 & 1992 & 2007 & 1982 & 2007 \\
\hline Médias nacionais & 50,42 & 60,51 & 78,89 & 20,52 & 26,43 & 63,04 & 10,91 & 14,41 & 41,21 & 11,32 & 11,49 \\
\hline \multicolumn{12}{|l|}{ Sexo } \\
\hline Mulheres & 54,43 & 67,88 & 82,29 & 23,88 & 31,75 & 70,78 & 13,22 & 17,98 & 48,48 & 12,80 & 13,19 \\
\hline Homens & 46,98 & 54,32 & 76,03 & 17,63 & 21,96 & 56,50 & 8,94 & 11,42 & 35,08 & 10,05 & 10,05 \\
\hline \multicolumn{12}{|l|}{ Sexo do chefe do domicílio } \\
\hline Mulheres & 45,65 & 57,08 & 76,39 & 17,25 & 23,18 & 61,22 & 8,67 & 12,65 & 39,13 & 8,75 & 10,53 \\
\hline Homens & 51,19 & 61,22 & 79,88 & 21,04 & 27,10 & 63,75 & 11,28 & 14,78 & 42,03 & 11,73 & 11,86 \\
\hline \multicolumn{12}{|l|}{ Urbanização } \\
\hline Rural & 28,82 & 40,01 & 75,29 & 5,60 & 8,86 & 42,51 & 2,32 & 4,08 & 24,41 & 3,58 & 1,96 \\
\hline Urbano & 59,91 & 67,00 & 79,74 & 27,07 & 31,99 & 67,85 & 14,69 & 17,69 & 45,15 & 14,74 & 13,72 \\
\hline \multicolumn{12}{|l|}{ Escolaridade da mãe } \\
\hline Sem esc. formal & 33,30 & 41,44 & 71,48 & 5,71 & 7,94 & 36,55 & 2,18 & 3,08 & 18,92 & 3,52 & 1,03 \\
\hline Ensino fundamental & 58,22 & 64,23 & 77,66 & 25,80 & 27,89 & 58,55 & 13,23 & 14,34 & 36,12 & 12,84 & 3,75 \\
\hline Ensino médio & 91,16 & 89,29 & 84,08 & 68,02 & 60,39 & 79,58 & 45,77 & 38,36 & 56,54 & 50,68 & 19,49 \\
\hline Ensino superior & 94,99 & 95,61 & 88,41 & 83,15 & 78,59 & 90,65 & 60,34 & 54,78 & 67,04 & 59,71 & 49,89 \\
\hline \multirow[t]{3}{*}{ N. abs. } & 38.276 & 21.508 & 23.784 & 38.276 & 21.508 & 23.784 & 38.276 & 21.508 & 23.784 & 37.298 & 23.158 \\
\hline & \multicolumn{11}{|c|}{ México } \\
\hline & 1984 & 1992 & 2008 & 1984 & 1992 & 2008 & 1984 & 1992 & 2008 & 1992 & 2008 \\
\hline Médias nacionais & 52,07 & 49,71 & 62,30 & 79,50 & 87,36 & 95,67 & 16,99 & 21,42 & 37,97 & 12,32 & 9,30 \\
\hline \multicolumn{12}{|l|}{ Sexo } \\
\hline Mulheres & 53,59 & 51,92 & 64,17 & 79,16 & 88,46 & 96,22 & 15,55 & 24,89 & 42,15 & 15,14 & 9,48 \\
\hline Homens & 50,75 & 47,60 & 61,64 & 79,81 & 86,31 & 95,19 & 18,23 & 18,11 & 34,25 & 9,64 & 9,14 \\
\hline \multicolumn{12}{|l|}{ Sexo do chefe do domicílio } \\
\hline Mulheres & 43,63 & 48,23 & 61,26 & 81,86 & 89,10 & 94,85 & 13,50 & 28,00 & 36,24 & 12,79 & 10,00 \\
\hline Homens & 53,16 & 49,89 & 62,58 & 79,20 & 87,15 & 95,89 & 17,44 & 20,64 & 38,46 & 12,26 & 9,12 \\
\hline \multicolumn{12}{|l|}{ Urbanização } \\
\hline Rural & 36,68 & 26,41 & 48,20 & 63,24 & 71,07 & 91,11 & 7,36 & 6,48 & 26,66 & 3,19 & 2,14 \\
\hline Urbano & 61,24 & 57,64 & 67,04 & 89,20 & 92,90 & 97,21 & 22,72 & 26,50 & 41,77 & 15,44 & 11,71 \\
\hline \multicolumn{12}{|l|}{ Escolaridade da mãe } \\
\hline Sem esc. formal & 39,36 & 25,99 & 37,11 & 60,49 & 69,92 & 84,58 & 4,60 & 8,65 & 17,86 & 3,42 & 2,93 \\
\hline Ensino fundamental & 52,47 & 48,13 & 51,61 & 84,64 & 90,67 & 94,74 & 16,03 & 17,04 & 30,97 & 9,32 & 4,22 \\
\hline Ensino médio & 90,36 & 84,47 & 74,83 & 98,79 & 98,14 & 99,03 & 57,93 & 50,96 & 46,59 & 30,79 & 11,62 \\
\hline Ensino superior & 100,00 & 96,54 & 91,96 & 100,00 & 100,00 & 98,90 & 74,81 & 70,54 & 62,28 & 53,77 & 32,71 \\
\hline N. abs. & 1.926 & 4.088 & 8.547 & 1.926 & 4.088 & 8.547 & 1.926 & 4.088 & 8.547 & 4.076 & 8.525 \\
\hline
\end{tabular}

Fonte: IBGE. PNAD 1982, 1992 e 2007; ENIGH 1984, 1992 e 2008. 
TABELA 4

Probabilidades de matrícula escolar para adolescentes de 15 a 18 anos, segundo variáveis selecionadas Brasil e México - 1982-2008

\begin{tabular}{|c|c|c|c|c|c|c|}
\hline \multirow{2}{*}{ Variáveis selecionadas } & \multicolumn{3}{|c|}{ Brasil } & \multicolumn{3}{|c|}{ México } \\
\hline & 1982 & 1992 & 2007 & 1984 & 1992 & 2008 \\
\hline \multirow[t]{2}{*}{ Idade } & $-0,225^{\star * *}$ & $-0,227^{* * *}$ & $-0,490 * \star \star$ & $-0,298 * \star *$ & $-0,296^{\star * *}$ & $-0,319 * * *$ \\
\hline & $(0,01)$ & $(0,01)$ & $(0,01)$ & $(0,04)$ & $(0,03)$ & $(0,02)$ \\
\hline \multirow[t]{2}{*}{ Mulher } & $0,167^{\star \star \star *}$ & $0,347^{\star \star *}$ & $0,208^{* \star *}$ & 0,033 & $0,114^{\star}$ & $0,109 * *$ \\
\hline & $(0,02)$ & $(0,02)$ & $(0,02)$ & $(0,09)$ & $(0,07)$ & $(0,04)$ \\
\hline \multirow[t]{2}{*}{ Escolaridade da mãe } & $0,143^{\star * *}$ & $0,114^{\star \star \star}$ & $0,051^{* * *}$ & $0,094^{\star \star \star}$ & $0,133^{\star \star \star}$ & $0,097^{\star \star *}$ \\
\hline & $(0,00)$ & $(0,00)$ & $(0,00)$ & $(0,02)$ & $(0,01)$ & $(0,01)$ \\
\hline \multirow[t]{2}{*}{ Domicílios chefiados por mulher } & $-0,211 * \star \star *$ & $-0,182^{\star \star *}$ & $-0,148^{\star \star \star}$ & $-0,431^{* * *}$ & $-0,231^{* *}$ & $-0,074$ \\
\hline & $(0,02)$ & $(0,03)$ & $(0,03)$ & $(0,13)$ & $(0,10)$ & $(0,05)$ \\
\hline \multirow[t]{2}{*}{ Log da renda domiciliar per capita } & $0,201 * * *$ & $0,181^{\star \star *}$ & $0,062^{\star \star *}$ & $0,291 * * \star$ & $0,349 * \star \star$ & $0,250^{\star * *}$ \\
\hline & $(0,01)$ & $(0,01)$ & $(0,02)$ & $(0,09)$ & $(0,05)$ & $(0,03)$ \\
\hline \multirow[t]{2}{*}{ Área urbana } & $0,562^{\star \star *}$ & $0,415^{\star \star \star}$ & $0,066^{\star \star}$ & $0,368^{\star \star \star}$ & $0,419 * \star \star$ & $0,147^{\star \star \star}$ \\
\hline & $(0,02)$ & $(0,03)$ & $(0,03)$ & $(0,10)$ & $(0,09)$ & $(0,05)$ \\
\hline \multirow[t]{2}{*}{ Constante } & $0,961 * * *$ & $0,825^{\star \star \star}$ & $8,179^{\star \star *}$ & $1,963^{*}$ & $-0,357$ & $2,896^{\star \star \star}$ \\
\hline & $(0,15)$ & $(0,22)$ & $(0,21)$ & $(1,05)$ & $(0,78)$ & $(0,39)$ \\
\hline N. abs. & 36.811 & 19.884 & 20.421 & 1.880 & 4.015 & 8.358 \\
\hline
\end{tabular}

Fonte: IBGE. PNAD 1982, 1992 e 2007; ENIGH 1984, 1992 e 2008.

*** $p<0,01 ; * * p<0,05 ; p<0,1$.

Nota: Os dados entre parêntesis correspondem a erros-padrão robustos. Regiões também foram utilizadas como controle.

\section{GRÁFICO 5}

Probabilidades preditas de matrícula no ensino Fundamental para adolescentes de 15 a 18 anos, segundo escolaridade da mãe

Brasil e México 1982-2008

Brasil

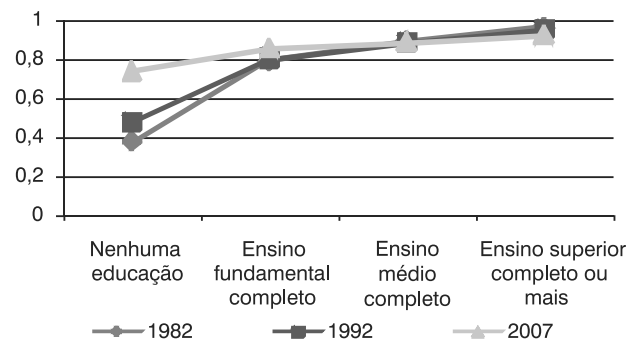

Fonte: IBGE. PNAD; ENIGH.

A Tabela 5 reporta os coeficientes para as probabilidades de completar o ensino fundamental incondicionais e condicionais à entrada na primeira série. Apesar de a origem social ter um efeito positivo e estatisticamente significante em todo o período estudado, há importantes mudanças na magnitude das associações durante os 35 anos avaliados.

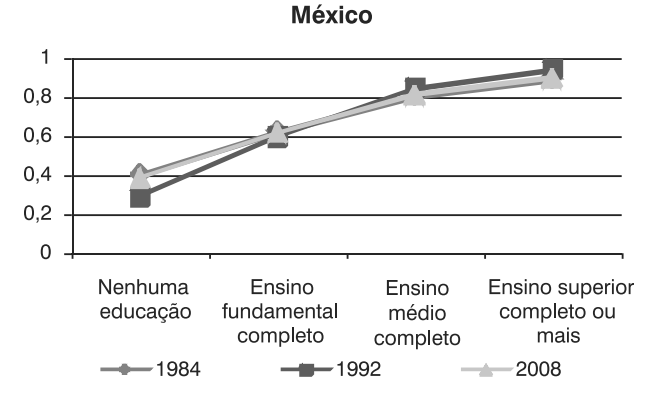

A associação entre origem social e probabilidade de completar o ensino fundamental enfraqueceu nos dois países durante o período estudado. Enquanto entre os anos 1980 e 1990 as associações permaneceram praticamente estáveis, entre as décadas de 1980 e 2000 declinaram significativamente para os dois países (diferenças entre os coeficientes dos anos 1980 e 2000 estatisti- 
TABELA 5

Probabilidades de conclusão do ensino fundamental e transições incondicionais e condicionais para o ensino médio para adolescentes de 15 a 18 anos, segundo variáveis selecionadas

Brasil - 1982-2007

\begin{tabular}{|c|c|c|c|c|c|c|}
\hline \multirow[b]{3}{*}{ Variáveis selecionadas } & \multicolumn{6}{|c|}{ Transições incondicionais } \\
\hline & \multicolumn{2}{|c|}{1982} & \multicolumn{2}{|c|}{1992} & \multicolumn{2}{|c|}{2007} \\
\hline & $\begin{array}{l}\text { Completar } \\
\text { o ensino } \\
\text { fundamental }\end{array}$ & $\begin{array}{c}\text { Transição } \\
\text { para o } \\
\text { ensino } \\
\text { médio } \\
\end{array}$ & $\begin{array}{l}\text { Completar } \\
\text { o ensino } \\
\text { fundamental }\end{array}$ & $\begin{array}{c}\text { Transição } \\
\text { para o } \\
\text { ensino } \\
\text { médio } \\
\end{array}$ & $\begin{array}{l}\text { Completar } \\
\text { o ensino } \\
\text { fundamental }\end{array}$ & $\begin{array}{c}\text { Transição } \\
\text { para o ensino } \\
\text { médio }\end{array}$ \\
\hline \multirow[t]{2}{*}{ Idade } & $0,346^{\star \star \star}$ & $0,496^{\star \star \star}$ & $0,321 * \star \star$ & $0,481^{\star \star *}$ & $0,382^{\star \star \star}$ & $0,647^{\star \star \star *}$ \\
\hline & $(0,01)$ & $(0,01)$ & $(0,01)$ & $(0,01)$ & $(0,01)$ & $(0,01)$ \\
\hline \multirow[t]{2}{*}{ Mulher } & $0,304^{\star \star \star}$ & $0,330^{\star \star \star}$ & $0,380^{\star * *}$ & $0,389^{\star \star \star}$ & $0,487^{\star \star \star}$ & $0,492^{\star \star \star}$ \\
\hline & $(0,02)$ & $(0,02)$ & $(0,02)$ & $(0,03)$ & $(0,02)$ & $(0,02)$ \\
\hline \multirow[t]{2}{*}{ Escolaridade da mãe } & $0,127^{\star \star \star}$ & $0,107^{\star * *}$ & $0,108^{\star \star \star}$ & $0,103^{\star * *}$ & $0,085^{\star \star \star}$ & $0,075^{\star \star \star}$ \\
\hline & $(0,00)$ & $(0,00)$ & $(0,00)$ & $(0,00)$ & $(0,00)$ & $(0,00)$ \\
\hline \multirow[t]{2}{*}{ Domicílio chefiado por mulher } & $-0,144^{\star \star *}$ & $-0,144^{\star \star *}$ & $-0,175^{\star \star *}$ & $-0,151 * * *$ & $-0,157^{\star \star *}$ & $-0,178^{\star * *}$ \\
\hline & $(0,03)$ & $(0,04)$ & $(0,03)$ & $(0,04)$ & $(0,02)$ & $(0,03)$ \\
\hline \multirow[t]{2}{*}{ Área urbana } & $0,466^{\star \star \star}$ & $0,419^{\star \star \star}$ & $0,351^{\star \star \star}$ & $0,332^{\star \star \star}$ & $0,130^{\star \star \star}$ & $0,117^{\star \star \star}$ \\
\hline & $(0,03)$ & $(0,04)$ & $(0,04)$ & $(0,05)$ & $(0,03)$ & $(0,03)$ \\
\hline \multirow[t]{2}{*}{$\begin{array}{l}\text { Log da renda domiciliar } \\
\text { per capita }\end{array}$} & $0,496^{\star \star \star}$ & $0,526^{\star \star \star}$ & $0,395^{\star \star \star}$ & $0,351 * \star \star *$ & $0,268^{\star \star \star}$ & $0,269 * \star \star *$ \\
\hline & $(0,02)$ & $(0,02)$ & $(0,02)$ & $(0,02)$ & $(0,02)$ & $(0,02)$ \\
\hline \multirow[t]{2}{*}{ Constante } & $-12,10^{\star * *}$ & $-15,47^{\star \star *}$ & $-11,85^{\star \star *}$ & $-14,54^{\star \star *}$ & $-7,99 * * *$ & $-13,08^{\star * *}$ \\
\hline & $(0,22)$ & $(0,28)$ & $(0,29)$ & $(0,38)$ & $(0,19)$ & $(0,22)$ \\
\hline N. abs. & 36.811 & 36.811 & 19.884 & 19.884 & 20.421 & 20.421 \\
\hline
\end{tabular}

(continuação)

\begin{tabular}{|c|c|c|c|c|c|c|}
\hline \multirow[b]{3}{*}{ Variáveis selecionadas } & \multicolumn{6}{|c|}{ Transições condicionais } \\
\hline & \multicolumn{2}{|c|}{1982} & \multicolumn{2}{|c|}{1992} & \multicolumn{2}{|c|}{2007} \\
\hline & $\begin{array}{l}\text { Completar } \\
\text { o ensino } \\
\text { fundamental }\end{array}$ & $\begin{array}{c}\text { Transição } \\
\text { para o } \\
\text { ensino } \\
\text { médio } \\
\end{array}$ & $\begin{array}{l}\text { Completar } \\
\text { o ensino } \\
\text { fundamental }\end{array}$ & $\begin{array}{c}\text { Transição } \\
\text { para o } \\
\text { ensino } \\
\text { médio }\end{array}$ & $\begin{array}{l}\text { Completar } \\
\text { o ensino } \\
\text { fundamental }\end{array}$ & $\begin{array}{c}\text { Transição } \\
\text { para o } \\
\text { ensino } \\
\text { médio }\end{array}$ \\
\hline \multirow[t]{2}{*}{ Idade } & $0,351^{\star \star *}$ & $0,459^{\star \star \star}$ & $0,328^{\star \star *}$ & $0,469 * \star \star$ & $0,384^{\star \star *}$ & $0,657^{\star * \star}$ \\
\hline & $(0,01)$ & $(0,02)$ & $(0,01)$ & $(0,02)$ & $(0,01)$ & $(0,01)$ \\
\hline \multirow[t]{2}{*}{ Mulher } & $0,293^{\star * *}$ & $0,191^{\star \star *}$ & $0,368^{\star * *}$ & $0,224^{\star \star \star}$ & $0,499 * \star *$ & $0,342^{\star * *}$ \\
\hline & $(0,02)$ & $(0,03)$ & $(0,02)$ & $(0,04)$ & $(0,02)$ & $(0,03)$ \\
\hline \multirow[t]{2}{*}{ Escolaridade da mãe } & $0,124^{\star \star *}$ & $0,052^{\star \star *}$ & $0,106^{\star \star *}$ & $0,059^{\star \star \star}$ & $0,086^{\star \star *}$ & $0,046^{\star \star \star}$ \\
\hline & $(0,00)$ & $(0,01)$ & $(0,00)$ & $(0,01)$ & $(0,00)$ & $(0,00)$ \\
\hline \multirow[t]{2}{*}{ Domicílio chefiado por mulher } & $-0,138^{* * *}$ & $-0,084$ & $-0,175^{\star \star \star}$ & $-0,051$ & $-0,155^{\star \star \star}$ & $-0,149^{\star \star \star *}$ \\
\hline & $(0,03)$ & $(0,05)$ & $(0,03)$ & $(0,06)$ & $(0,02)$ & $(0,03)$ \\
\hline \multirow[t]{2}{*}{ Área urbana } & $0,439 * \star \star$ & 0,062 & $0,339 * * \star$ & 0,067 & $0,137^{\star * *}$ & 0,028 \\
\hline & $(0,03)$ & $(0,07)$ & $(0,04)$ & $(0,08)$ & $(0,03)$ & $(0,04)$ \\
\hline \multirow[t]{2}{*}{$\begin{array}{l}\text { Log da renda domiciliar } \\
\text { per capita }\end{array}$} & $0,489^{\star \star \star}$ & $0,314^{\star \star *}$ & $0,391 * \star \star$ & $0,150^{\star \star \star}$ & $0,281 * \star \star$ & $0,189 * \star \star$ \\
\hline & $(0,02)$ & $(0,02)$ & $(0,02)$ & $(0,03)$ & $(0,02)$ & $(0,02)$ \\
\hline \multirow[t]{2}{*}{ Constante } & $-12,07^{\star \star \star}$ & $-11,27^{\star \star \star}$ & $-11,86^{\star \star \star}$ & $-10,30 * \star \star$ & $-8,08^{\star \star \star}$ & $-12,05^{\star \star \star}$ \\
\hline & $(0,22)$ & $(0,39)$ & $(0,29)$ & $(0,50)$ & $(0,20)$ & $(0,27)$ \\
\hline N. abs. & 33.751 & 8.094 & 18.768 & 5.263 & 19.903 & 12.912 \\
\hline
\end{tabular}

Fonte: IBGE. PNAD 1982, 1992 e 2007.

$* * * p<0.01,{ }^{* *} p<0.05,{ }^{*} p<0.1$.

Nota: Os dados entre parêntesis correspondem a erros-padrão robustos

Também controlado pelas regiões do país: Norte, Nordeste, Sul, Sudeste e Centro-Oeste. 
camente significantes, $p<0,01)$. O Gráfico 6 mostra que, por exemplo, mantendo constante todas as outras variáveis em suas médias, nos anos 1980 as crianças mexicanas com mães com ensino superior tinham 30 pontos percentuais a mais de chances de completar o ensino fundamental do que seus pares que tinham mães sem escolaridade formal. Essa diferença caiu para 8 pontos percentuais na década de 2000 . No caso brasileiro, nos anos 1980 a probabilidade de completar o ensino fundamental era 61 pontos percentuais maior para adolescentes com mães com ensino superior do que para aqueles com mães sem escolaridade formal; essa diferença caiu para 54 pontos percentuais na década de 1990 e para 41 na de 2000. Apesar de a magnitude dos coeficientes ter diminuído para todo o período avaliado, os declínios mais fortes ocorreram entre a década de 1990 e o final dos anos 2000 , período marcado por crescimento econômico e uma série de políticas públicas focadas na inclusão e manutenção de crianças de baixo status socioeconômico no sistema educacional. Entretanto, ainda existe uma desvantagem significativa na probabilidade de conclusão do ensino fundamental para adolescentes brasileiros com origem social baixa em relação àqueles com origem social elevada, situação essa que praticamente inexiste no México.

A Tabela 6 traz os modelos calculados para a probabilidade de transição para o ensino médio. Enquanto entre as décadas de 1980 e 1990 os coeficientes relativos às transições incondicionais se mantiveram praticamente estáveis, entre os anos 1990 e 2000 caíram significativamente (a diferença entre os coeficientes de 1990 e 2000 é estatisticamente significante $p<0,05)$. Como esperado, a magnitude da associação relativa às transições condicionais é menor do que para as transições incondicionais. A associação se manteve praticamente estável entre as décadas de 1980 e 1990. Durante os anos 2000, no entanto, a associação caiu apenas levemente no Brasil (coeficiente: 0,052 na década de 1980 e 0,046 na de 2000 , com diferenças estatisticamente insignificantes). Quando considerado todo o período, observa-se que a associação entre origem social familiar e transição para o ensino médio condicional ao término do nível anterior diminuiu de maneira significativa no México (coeficiente: 0,092 na década de 1980 e 0,058 na de 2000 , com diferenças estatisticamente significantes ao nível 0,01 ), mas não no Brasil, o que confirma parcialmente a hipótese de magnitudes diferentes do impacto da origem social nas transições educacionais dependendo do nível de universalização do nível de ensino anterior, neste caso, o ensino fundamental.

Os resultados da associação entre origem social e matrícula em escolas privadas - uma proxy da qualidade educacional tanto no Brasil quanto no México - encontram-se na Tabela 7. Os coeficientes de escolaridade materna mostram que, no Brasil, a asso-

GRÁFICO 6

Probabilidades preditas de completar o ensino fundamental (condicional) para adolescentes de 15 a 18 anos, segundo escolaridade da mãe Brasil e México - 1982-2008

Brasil

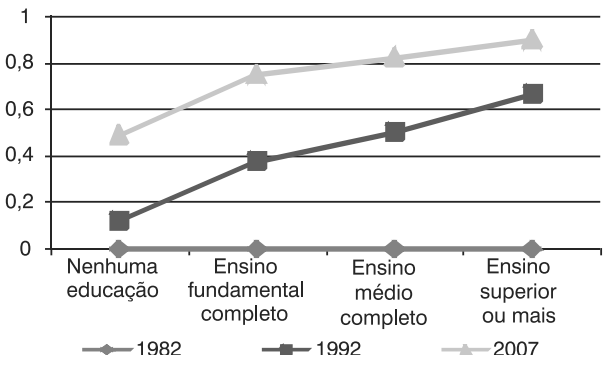

México

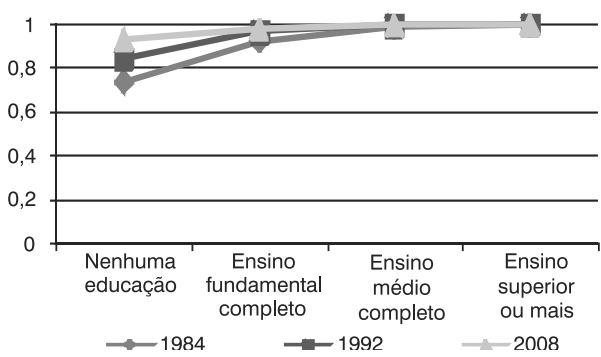

Fonte: IBGE. PNAD; ENIGH. 
TABELA 6

Probabilidades de conclusão do ensino fundamental e transições incondicionais e condicionais para o ensino médio para adolescentes de 15 a 18 anos, segundo variáveis selecionadas México - 1984-2008

\begin{tabular}{|c|c|c|c|c|c|c|}
\hline \multirow{3}{*}{$\begin{array}{l}\text { Variáveis } \\
\text { selecionadas }\end{array}$} & \multicolumn{6}{|c|}{ Transições incondicionais } \\
\hline & \multicolumn{2}{|c|}{1984} & \multicolumn{2}{|c|}{1992} & \multicolumn{2}{|c|}{2008} \\
\hline & $\begin{array}{l}\text { Completar } \\
\text { o ensino } \\
\text { fundamental }\end{array}$ & $\begin{array}{l}\text { Transição } \\
\text { para o ensino } \\
\text { médio }\end{array}$ & $\begin{array}{l}\text { Completar } \\
\text { o ensino } \\
\text { fundamental }\end{array}$ & $\begin{array}{l}\text { Transição } \\
\text { para o ensino } \\
\text { médio }\end{array}$ & $\begin{array}{l}\text { Completar } \\
\text { o ensino } \\
\text { fundamental }\end{array}$ & $\begin{array}{l}\text { Transição } \\
\text { para o ensino } \\
\text { médio }\end{array}$ \\
\hline \multirow{2}{*}{ Idade } & $-0,044$ & $0,290^{\star * *}$ & 0,026 & $0,383^{\star \star \star}$ & 0,035 & $0,601^{* \star *}$ \\
\hline & $(0,05)$ & $(0,05)$ & $(0,04)$ & $(0,04)$ & $(0,03)$ & $(0,02)$ \\
\hline \multirow{2}{*}{ Mulher } & $-0,052$ & $-0,130$ & 0,099 & $0,297^{\star \star \star *}$ & $0,153^{\star}$ & $0,264^{\star \star \star}$ \\
\hline & $(0,11)$ & $(0,13)$ & $(0,09)$ & $(0,08)$ & $(0,08)$ & $(0,05)$ \\
\hline \multirow{2}{*}{ Escolaridade da mãe } & $0,149 * \star \star$ & $0,122^{\star \star \star}$ & $0,138^{\star \star \star}$ & $0,099^{\star \star \star}$ & $0,084^{\star \star \star}$ & $0,081^{\star \star *}$ \\
\hline & $(0,02)$ & $(0,02)$ & $(0,02)$ & $(0,01)$ & $(0,01)$ & $(0,01)$ \\
\hline \multirow{2}{*}{$\begin{array}{l}\text { Domicílio chefiado } \\
\text { por mulher }\end{array}$} & $-0,132$ & $-0,414^{\star *}$ & $-0,137$ & $-0,035$ & $-0,208^{* *}$ & $-0,121 * *$ \\
\hline & $(0,18)$ & $(0,18)$ & $(0,12)$ & $(0,10)$ & $(0,10)$ & $(0,06)$ \\
\hline \multirow{2}{*}{ Área urbana } & $0,565^{\star \star \star}$ & $0,243^{*}$ & $0,416^{\star \star \star}$ & $0,474 * \star \star$ & 0,089 & $0,102^{*}$ \\
\hline & $(0,12)$ & $(0,13)$ & $(0,11)$ & $(0,12)$ & $(0,09)$ & $(0,06)$ \\
\hline \multirow{2}{*}{$\begin{array}{l}\text { Log da renda } \\
\text { domiciliar per capita }\end{array}$} & $0,296^{\star \star \star}$ & $0,368^{\star \star \star}$ & $0,445^{\star \star \star}$ & 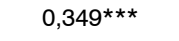 & $0,293^{\star \star \star}$ & $0,207^{\star \star \star}$ \\
\hline & $(0,10)$ & $(0,10)$ & $(0,07)$ & $(0,05)$ & $(0,06)$ & $(0,04)$ \\
\hline \multirow{2}{*}{ Constante } & $-2,09$ & $-10,28^{\star \star \star}$ & $-6,03^{\star \star \star}$ & $-12,46^{\star \star \star}$ & $-1,88^{\star \star *}$ & $-12,63^{\star \star *}$ \\
\hline & $(1,29)$ & $(1,40)$ & $(1,02)$ & $(0,96)$ & $(0,67)$ & $(0,46)$ \\
\hline N. abs. & 1.880 & 1.880 & 4.015 & 4.015 & 8.358 & 8.358 \\
\hline \multirow{2}{*}{\multicolumn{7}{|c|}{ (continuação) }} \\
\hline & & & & & & \\
\hline \multirow{3}{*}{$\begin{array}{l}\text { Variáveis } \\
\text { selecionadas }\end{array}$} & \multicolumn{6}{|c|}{ Transições condicionais } \\
\hline & \multicolumn{2}{|c|}{1984} & \multicolumn{2}{|c|}{1992} & \multicolumn{2}{|c|}{2008} \\
\hline & $\begin{array}{l}\text { Completar } \\
\text { o ensino } \\
\text { fundamental }\end{array}$ & $\begin{array}{c}\text { Transição } \\
\text { para o ensino } \\
\text { médio }\end{array}$ & $\begin{array}{l}\text { Completar } \\
\text { o ensino } \\
\text { fundamental }\end{array}$ & $\begin{array}{c}\text { Transição } \\
\text { para o ensino } \\
\text { médio }\end{array}$ & $\begin{array}{l}\text { Completar } \\
\text { o ensino } \\
\text { fundamental }\end{array}$ & $\begin{array}{c}\text { Transição } \\
\text { para o ensino } \\
\text { médio }\end{array}$ \\
\hline \multirow{2}{*}{ Idade } & $-0,022$ & $0,220^{* \star *}$ & 0,011 & $0,338^{\star \star \star}$ & $0,082^{\star \star}$ & $0,602^{\star \star \star}$ \\
\hline & $(0,05)$ & $(0,07)$ & $(0,04)$ & $(0,04)$ & $(0,04)$ & $(0,03)$ \\
\hline \multirow{2}{*}{ Mulher } & $-0,055$ & $-0,158$ & 0,101 & $0,187^{\star *}$ & $0,166^{\star}$ & $0,173^{\star \star \star}$ \\
\hline & $(0,11)$ & $(0,15)$ & $(0,09)$ & $(0,09)$ & $(0,09)$ & $(0,05)$ \\
\hline \multirow{2}{*}{ Escolaridade da mãe } & $0,133^{\star * *}$ & $0,092^{\star \star \star}$ & $0,136^{\star * *}$ & $0,078^{\star \star *}$ & $0,089^{\star \star *}$ & $0,058^{\star \star *}$ \\
\hline & $(0,02)$ & $(0,03)$ & $(0,02)$ & $(0,01)$ & $(0,01)$ & $(0,01)$ \\
\hline \multirow{2}{*}{$\begin{array}{l}\text { Domicílio chefiado } \\
\text { por mulher }\end{array}$} & $-0,070$ & $-0,508^{\star *}$ & $-0,089$ & 0,003 & $-0,205^{\star}$ & $-0,065$ \\
\hline & $(0,20)$ & $(0,22)$ & $(0,13)$ & $(0,12)$ & $(0,11)$ & $(0,06)$ \\
\hline \multirow{2}{*}{ Área urbana } & $0,532^{\star \star *}$ & $-0,015$ & $0,427^{\star \star \star}$ & $0,257^{\star}$ & 0,063 & 0,061 \\
\hline & $(0,13)$ & $(0,18)$ & $(0,11)$ & $(0,15)$ & $(0,10)$ & $(0,07)$ \\
\hline \multirow{2}{*}{$\begin{array}{l}\text { Log da renda domiciliar } \\
\text { per capita }\end{array}$} & $0,299^{\star \star \star}$ & $0,432^{\star \star \star}$ & $0,377^{\star \star \star}$ & $0,268^{\star \star \star}$ & $0,271^{\star \star *}$ & $0,168^{\star \star \star}$ \\
\hline & $(0,11)$ & $(0,12)$ & $(0,07)$ & $(0,07)$ & $(0,07)$ & $(0,04)$ \\
\hline \multirow{2}{*}{ Constante } & $-2,32^{*}$ & $-8,50^{\star \star *}$ & $-4,73^{\star \star \star}$ & $-9,58^{\star \star \star}$ & $-2,37^{\star \star \star}$ & $-11,76^{\star \star \star}$ \\
\hline & $(1,37)$ & $(1,68)$ & $(1,06)$ & $(1,17)$ & $(0,73)$ & $(0,52)$ \\
\hline N. abs. & 1.833 & 812 & 3.900 & 1.985 & 8.290 & 6.195 \\
\hline
\end{tabular}

Fonte: ENIGH 1984, 1992 e 2008.

*** $p<0.01,{ }^{* *} p<0.05,{ }^{*} p<0.1$

Nota: Os dados entre parêntesis correspondem a erros-padrão robustos.

As sete principais regiões do México também foram usadas como controle. 
TABELA 7

Probabilidades de matrícula em escola privada para adolescentes de 15 a 18 anos, segundo variáveis selecionadas Brasil e México (1) - 1982-2008

\begin{tabular}{|c|c|c|c|c|}
\hline \multirow{2}{*}{ Variáveis selecionadas } & \multicolumn{2}{|c|}{ Brasil (2) } & \multicolumn{2}{|c|}{ México(2) } \\
\hline & 1982 & 2007 & 1992 & 2008 \\
\hline \multirow[t]{2}{*}{ Idade } & $0,134 * * *$ & $0,146^{\star \star *}$ & $0,123^{\star \star \star}$ & $0,160 * * *$ \\
\hline & $(0,01)$ & $(0,02)$ & $(0,04)$ & $(0,03)$ \\
\hline \multirow[t]{2}{*}{ Mulher } & $0,081^{* * *}$ & $0,196^{\star \star \star}$ & $0,277^{\star \star \star}$ & 0,042 \\
\hline & $(0,02)$ & $(0,03)$ & $(0,10)$ & $(0,07)$ \\
\hline \multirow[t]{2}{*}{ Escolaridade da mãe } & $0,080^{\star \star \star}$ & $0,103^{\star \star \star}$ & $0,035^{\star \star}$ & $0,033^{\star * *}$ \\
\hline & $(0,00)$ & $(0,01)$ & $(0,01)$ & $(0,01)$ \\
\hline \multirow[t]{2}{*}{ Domicílio chefiado por mulher } & $-0,060$ & $-0,060$ & $-0,030$ & 0,031 \\
\hline & $(0,04)$ & $(0,04)$ & $(0,15)$ & $(0,07)$ \\
\hline \multirow[t]{2}{*}{ Log da renda familiar per capita } & $0,328^{* \star *}$ & $0,792^{\star \star \star}$ & $0,508^{* \star *}$ & $0,492^{\star \star \star}$ \\
\hline & $(0,02)$ & $(0,03)$ & $(0,07)$ & $(0,05)$ \\
\hline \multirow[t]{2}{*}{ Área urbana } & 0,003 & $0,315^{\star * *}$ & 0,193 & $0,252^{\star \star}$ \\
\hline & $(0,04)$ & $(0,07)$ & $(0,20)$ & $(0,11)$ \\
\hline \multirow[t]{2}{*}{ Constante } & $-6,45^{\star \star \star}$ & $-9,53^{\star * *}$ & $-10,90 * * *$ & $-8,83^{\star * *}$ \\
\hline & $(0,23)$ & $(0,30)$ & $(1,10)$ & $(0,66)$ \\
\hline N. abs. & 19.544 & 16.582 & 1.766 & 5.195 \\
\hline
\end{tabular}

Fonte: IBGE. PNAD 1982 e 2007; ENIGH 1992 e 2008.

*** $p<0.01,{ }^{* *} p<0.05,{ }^{*} p<0.1$

(1) Não há dados disponíveis para setor de matrícula para o Brasil em 1992 e México em 1984.

(2) Também controlando por região.

Nota: Os dados entre parêntesis correspondem a erros-padrão robustos.

\section{GRÁFICO 7}

Probabilidades preditas de transição para o ensino médio para adolescentes de 15 a 18 anos, segundo escolaridade da mãe

\section{Brasil e México - 1982-2008}
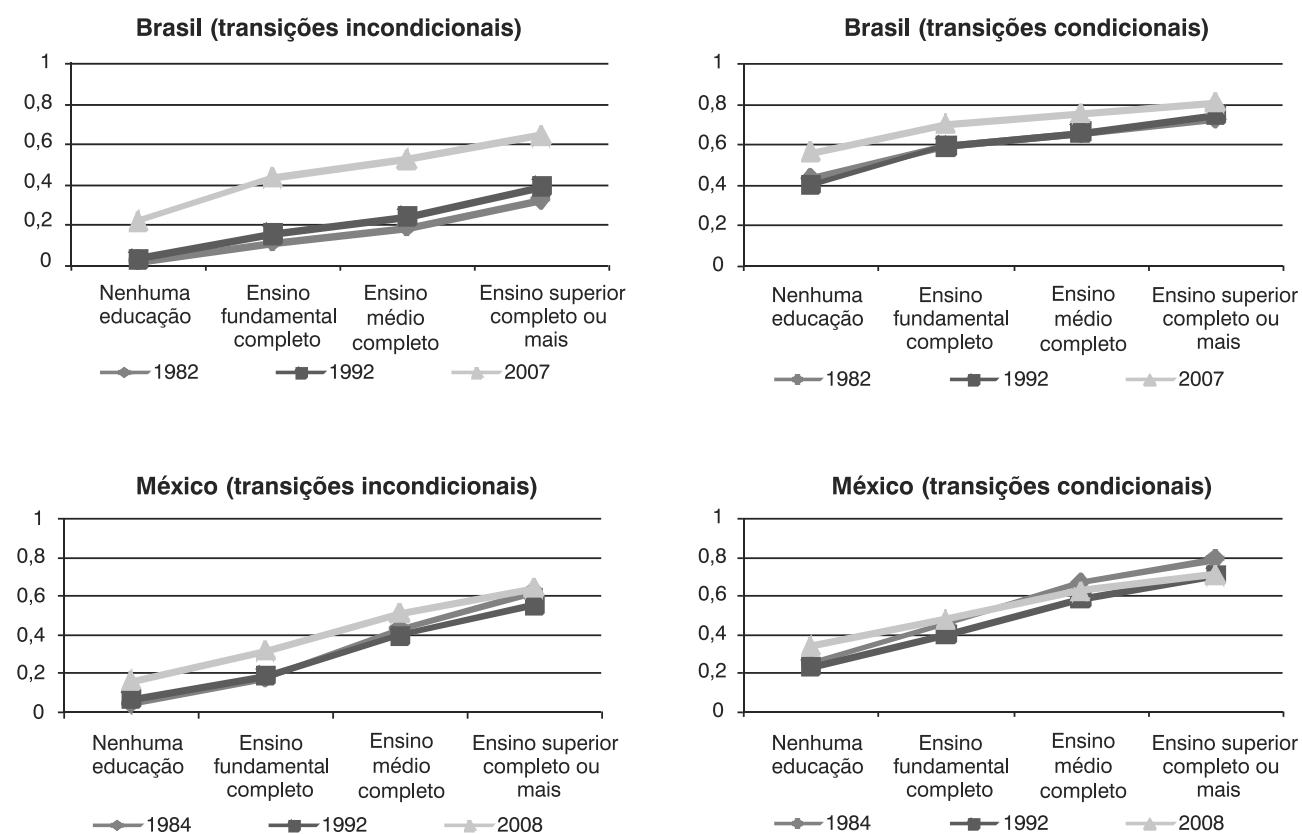

Fonte: IBGE. PNAD; ENIGH. 
ciação entre origem social e matrícula em escolas privadas aumentou sensivelmente ao longo do tempo, o que não aconteceu no México. No Brasil, verifica-se uma diferença estatisticamente significante entre as associações entre as décadas de 1980 e 2000 (coeficiente: 0,080 nos anos 1980 e 0,103 na década de 2000; diferença estatisticamente significativa ao nível 0,05). O México apresenta pequena queda na associação entre as desvantagens associadas à origem social na matrícula em escolas particulares entre as décadas de 1990 e 2000.

\section{Conclusões e discussão}

O objetivo deste artigo foi identificar mudanças nas desigualdades de oportunidades educacionais (tanto quantidade como qualidade) associadas à origem social da família ao longo das últimas três décadas no Brasil e México. Foram estudadas as desvantagens educacionais associadas à origem social dos adolescentes desde a "década perdida" dos anos 1980 até o fim dos anos 2000, quando Brasil e México viveram períodos de crescimento. Este trabalho contribui para a literatura sobre desigualdades de oportunidades educacionais por analisar diferentes coortes de jovens com trajetórias educacionais em períodos marcados por diferentes condições econômicas, ao mesmo tempo em que estende a análise para um período mais recente. Também analisou-se um importante aspecto da desigualdade educacional que a maioria dos estudos negligenciou: as tendências de desvantagens relativas à origem social associadas à qualidade da educação (medida pelo proxy da escola particular) durante um período longo.

Os resultados confirmam a importância das condições macroeconômicas e da universalização do ensino fundamental para desigualdades de oportunidades educacionais. O impacto da origem social na matrícula escolar caiu pela metade entre as década de 1980 e 2000 no Brasil, mas manteve-se estável no México. Entretanto, notouse também que, entre a década de 1990 e final dos anos 2000, a queda do papel da origem social na probabilidade de matrícula escolar não foi acompanhada por declínios significativos na proporção de adolescentes matriculados em escolas particulares. Isso sugere que a redução das desigualdades associadas à matrícula escolar, no Brasil, deve-se ao fato de adolescentes em posição de desvantagem passarem a ter maior acesso ao ensino público.

Também é interessante observar que, no Brasil - país com mais forte declínio na associação entre origem social e frequência à escola - também ocorreu um aumento da magnitude da associação entre origem social familiar e a matrícula na escola privada, o que sugere um fortalecimento das desigualdades no acesso à educação de qualidade.

Os resultados indicam quedas das desigualdades de conclusão do ensino fundamental baseadas na origem social entre as décadas de 1980 e 2000, tanto no Brasil como no México. As magnitudes da associação entre origem social e conclusão do ensino fundamental são similares no Brasil e no México ao final dos anos 2000. Isso demonstra o grande avanço em universalizar o ensino fundamental alcançado no Brasil no período estudado.

Apesar de a influência da origem social ter diminuído para a frequência escolar e para a conclusão do ensino fundamental, os resultados são menos inequívocos para as probabilidades de transição para o ensino médio. Encontraram-se pequenos declínios, quase estabilidade, na associação entre origem social e transições incondicionais para o ensino médio nos dois países, entre as décadas de 1980 e 1990, mas os resultados indicam quedas significativas ao longo dos anos 2000. As condições macroeconômicas da década de 2000, juntamente com a importante expansão educacional das últimas décadas, criaram condições para um número cada vez maior de adolescentes fazer a transição para a escola secundária.

Entretanto, os resultados relativos à probabilidade de transição ao ensino médio condicional ao término do ensino fundamental mostram um cenário diferente, indicando estabilidade na associação entre origem social e probabilidade de transição ao ensino médio condicional ao término do ensino fundamental, no caso brasileiro, entre 
as décadas de 1980 e de 2000. No México, a associação diminuiu. Era esperado que o caso mexicano apresentasse uma queda na magnitude da associação entre origem social e probabilidade de transição ao ensino médio condicional, uma vez que o país registrava universalização do ensino fundamental muito anterior ao Brasil, como discutido aqui. Essa diferença na diminuição das desvantagens associadas à origem social entre os países como consequência de diferentes estágios da universalização do nível de ensino anterior coincide com a perspectiva MMI.

Ao fim da última década, Brasil e México implementaram políticas significativas com o objetivo de melhorar seus resultados educacionais, particularmente relativos ao ingresso e à manutenção de adolescentes na escola. Esses programas focaram em manter crianças e adolescentes em situações desprivilegiadas no sistema educacional por meio de transferências de renda. Tais programas enfatizaram o acesso e permanência na escola e a quantidade educacional, mas a qualidade foi em grande parte omitida nesses esforços. Entretanto, o diferencial de qualidade entre escolas públicas e particulares no Brasil e no México também é um elemento crítico para a sus-

\section{Referências}

AUGUSTINE, J.; CAVANAGH, S.; CROSNOE, $R$. Maternal education, early child care and the reproduction of advantage. Social Forces, v. 88, n. 1, p. 1-20, 2009.

BARROS, R.; LAM, D. Income and educational inequality and children's schooling attainment. In: BIRDSALL, N.; SABOT, R. (Eds.). Opportunity foregone: education in Brazil. Washigton, DC: Inter-American Development Bank, 1996, p. 337-366.

BEHRMAN, J.; DURYEA, S.; SZEKELY, M. Schooling investments and aggregate conditions: a household-survey-based approach for Latin America and the Caribbean. Washigton, DC: Interamerican Development Bank, 1999 (Working paper, n. 407).

BEHRMAN, J.; SZÉKELY, M. Intergenerational tentação das desigualdades educacionais nestes países. A vantagem dos alunos de escolas particulares vis-à-vis alunos de escolas públicas na nota do Pisa em testes de matemática é de 106,73 pontos no Brasil, por exemplo (OECD, 2009). Pesquisas anteriores, de forma geral, falharam ao examinar esta significativa dimensão da desigualdade de oportunidade no contexto da expansão educacional no Brasil e no México ao Iongo das últimas décadas. Os resultados do presente estudo indicam uma persistência, e até mesmo aumento, na associação entre origem social e probabilidade de matrícula em escola particular, sugerindo que, apesar de as diferenças relativas ao status socioeconômico na quantidade da educação recebida terem de forma geral diminuído, as desvantagens associadas à qualidade da educação não sofreram o mesmo impacto. Ao contrário, essas associações cresceram de maneira significativa no Brasil, o que sugere a importância da perspectiva EMI por evidenciar desigualdades de oportunidades relativas a outras dimensões do sistema educacional (por exemplo, qualidade da educação, setor, curso, entre vários outros) para entendermos de modo mais completo a estratificação educacional no Brasil e México, e na América Latina de forma geral.

mobility in Latin Ameria. Economia, v. 2, n. 1, p. 1-44, 2001.

BINDER, M. Family background, gender and schooling in Mexico. Journal of Development Studies, v. 35, n. 2, p. 54-71, 1998.

BINDER, M.; WOODRUFF, C. Inequality and intergenerational mobility in schooling: the case of Mexico. Economic Developmeent and Cultural Change, v. 50, n. 2, p. 249267, 2002.

BIRDSALL, N.; SABOT, R. Opportunity foregone: education in Brazil. Washigton, DC: Inter-American Development Bank, 1996.

BOURDIEU, P.; PASSERON, J. C. Reproduction in education, society and culture. Londres: Sage, 1977 
BUCHMANN, C.; HANNUM, E. Education and stratification in developing countries: review of theories and empirical research. Annual Review of Sociology, v. 27, n. 1, p. 77-102, 2001.

CARNOY, M.; GOVE, A.; MARSHALL, J. Cuba's academic advantage: why students in Cuba do better in school. Standford, California: University Press, 2007.

CARRASCO, E. The 1980's: the debt crisis and the lost decade of development. Transnational Law \& Contemporary Problems, v. 119, 1999.

DURYEA, S.; LAM, D.; LEVISON, D. Effects of economic shocks on children's employment and schooling in Brazil. Journal of Development Economics, v. 84, n. 1, p. 188-214, 2007.

FILGUEIRA, C.; FILGUEIRA, F.; FUENTES, A. School attainment and transitions to adulthood in Latin America. In: DURYEA, S.; EDWARDS, A. et al. (Eds.). Critical choices at a critical age. Washigton D.C.: Inter-American Development Bank, 2003.

FRANCO, C.; ALVES, F.; BONAMINO, A. Qualidade do ensino fundamental: políticas, suas possibilidades, seus limites. Educação e Sociedade, Campinas, v. 28, n. 100 (Especial), p.989-1014, 2007.

GIORGULI-SAUCEDO, S. Estructuras familiares y oportunidades educativas de los niños e ninãs en México. Estudios Demográficos y Urbanos, v. 17, n. 1, p. 523-546, 2002.

GOMES-NETO, J. B.; HANUSHEK, E. Causes and consequences of grade repetition: evidence from Brazil. Economic Development and Cultural Change, v. 43, n. 1, p. 117-148, 1994.

GRANT, M. J.; BEHRMAN, J. Gender gaps in educational attainment in less developed countries. Population and Development Review, v. 36, n. 1, p. 71-89, 2010.

GUIMARÃES, R. R. D. M.; RIOS-NETO, E. L. G. Comparação entre metodologias de idade-período-coorte para o estudo de uma medida da progressão escolar no
Brasil. Revista Brasileira de Estudos de População, v. 28, n. 2, p. 349-367, 2011.

HANNUM, E.; BUCHMANN, C. Global educational expansion and socio-economic development: an assessment of findings from the social sciences. World Development, v. 33, p. 333-354, 2005.

LAM, D.; MARTELETO, L. Small families and large cohorts: the impact of the demographic transition on schooling in Brazil. In: LLOYD, C.; BEHRMAN, J. et al. (Eds.). The changing transitions to adulthood in developing countries: selected studies. Washington, DC: The National Academies Press, 2006.

Stages of the demographic transition from a child's perspective: family size, cohor size, and children's resources. Population and Development Review, v. 34, n. 2, p. 225-252, 2008.

LOPEZ-CALVA, L.; LUSTIG, N. Declining inequality in Latin America: a decade of progress? Washigton, DC: Brookings Institution Press, 2010.

LUCAS, S. Effectively maintained inequality: education transitions, track mobility and social background effects. American Journal of Sociology, v. 106, n. 6, p. 16421690, 2001.

MARTELETO, L. Educational inequality by race in Brazil, 1982-2007: Structural changes and shifts in racial classification. Demography, v. 49, n. 1, p. 337-358, 2012.

Changes in race inequalities in education in Brazil: 1982-2007. Demography, 2012, no prelo.

MARTELETO, L.; SOUZA, L. The impact of family size on children's educational attainment over time: assessing the exogenous variation in fertility usin twins in Brazil. Demography, 2012, no prelo.

MIER, M.; ROCHA, T.; ROMERO, C. R. Desigualdades en la escolaridad de los niños mexicanos. Revista Mexicana de Sociología, v. 64, n. 3, p. 63-89, 2002.

MONT'ALVÃO, A. Estratificação educacional do Brasil no século XXI. Dados, v. 54, n. 2, p. 389-430, 2012. 
NÉRI, M. O paradoxo da evasão e a motivação dos sem escola. In: VELOSO, F.; PESSOA, S. et al. (Eds.). Educação básica no Brasil: construindo o país do futuro. Rio de Janeiro: Campus, 2009.

OECD. Education at a glance: OECD indicators. OECD Publishing, 2009.

ORAZEM, P.; SEDLACEK, G.; TZANNATOS, $Z$. Child labor and education in Latin America: an economic perspective. New York: Palgrave Macmillan, 2009.

PARKER, S. Evaluación del impacto de oportunidades sobre la inscripción escolar: primaria, secundaria y media superior. Mexico: INSP-CIDE, 2003.

. Evaluación del impacto de Oportunidades sobre la inscripción, repoblación y abandono escolar. In: PRADO, B. H., ÁVILA, M. H. (Eds.). Evaluación externa del Programa Oportunidades 2003. México: INSP-CIESAS, 2005.

RIANI, J. D. L. R.; RIOS-NETO, E. L. G. Análise do dividendo demográfico na matrícula escolar no Brasil numa abordagem hierárquica e hierárquica-espacial. Revista Brasileira de Estudos de População, v. 24, n. 1, p. 69-90, 2007.

. Background familiar versus perfil escolar do município: qual possui maior impacto no resultado educacional dos alunos brasileiros? Revista Brasileira de Estudos de População, v. 25, n. 2, p. 251-259, 2008.

RIBEIRO, C. A. C. Class, race and social mobility in Brazil. Dados, v. 49, n. 4, p. 833873, 2007.

Desigualdade de oportunidades e resultados educacionais no Brasil. Dados, v. 54 , n. 1, p. 41-87, 2011 a.

. Desigualdade de oportunidades educacionais no Brasil: raça, classe e gênero. Educação On-Line (PUC-RJ), v. 8 , n. 1, p. 1-42, 2011b.

RIZO, F. M. Nueva visita al país de la desigualdad. La distribuición de la escolaridad en México, 1970-2000. Revista Mexicana de Investigación Educativa, v. 7, n. 16, p. 415-443, 2002.
RODRIGUES, C. G.; RIOS-NETO, E. L. G.; PINTO, C. C. D. X. Diferenças intertemporais na média e distribuição do desempenho escolar no Brasil: o papel do nível socioeconômico, 1997-2005. Revista Brasileira de Estudos de População, v. 28, n. 1, p. 5-36, 2011.

SAUCEDO, S. E. G.; VALLE, E. D. V.; ULLOA, V. S. et al. La dinámica demográfica y la desigualdad educativa en México. Estudios Demográficos y Urbanos, v. 25, n. 1, p. 7-44, 2010.

SCHULTZ, P. The impact of PROGRESA on school enrollments. Final report submitted to PROGRESA. Washigton, DC: International Food Policy Research Institute, 2000.

SHAVIT, Y.; BLOSSFELD, H. P. Persistent inequality: changing educational attainment in thirteen countries. Boulder, Colorado: Westview Press, 1993.

SILVA, N. D. V. Expansão escolar e estratificação educacional no Brasil. In: HASENBALG, C.; SILVA, N. D. V. (Eds.). Origens e destinos. Rio de Janeiro: Topbooks, 2003.

SILVA, N. D. V.; HASENBALG, C. Tendências da desigualdade educacional no Brasil. Dados, v. 43, n. 3, p. 423-445, 2000.

THORP, R. Progress, povery and exclusion. An economic history of Latin America in the 20th century. Baltimore: Johns Hopkins University Press, 1998.

TORCHE, F. Economic crisis and inequality of educational opportunity in Latin America. Sociology of Education, v. 83, n. 2, p. 85110, 2010.

TORCHE, F.; RIBEIRO, C. A. C. Parental wealth and children's outcomes over the lifecourse in Brazil: a propensity score matching analysis. Research in Mobility and Social Stratification, v. 30, n. 1, p. 79-96, 2012.

TREIMAN, D. Industrialization and social stratification. Sociological Inquiry, v. 40, n. 2, p. 207-234, 1970.

VELOSO, F. 15 anos de avanços na educação no Brasil: Onde estamos? In: VELOSO, F.; PESSOA, S. et al. (Eds.). Educação básica 
no Brasil: construindo o país do futuro. Rio de Janeiro: Elsevier, 2009, p.3-24.

ZORILLA, M. La educación secundaria en México: al filo de su reforma. REICE Revista Electrónica Iberoamericana sobre Calidad, Eficacia y Cambio en Educación, v. 2, n. 1, p. 1-22, 2004.
Diez años despés del Acuerdo Nacional para la Modernización de la Educación Básica en México: retos, tensiones y perspectivas. Revista Electrónica de Investigación Educativa, v. 4, n. 2, 2002.

\section{Resumen}

Desigualdad en las oportunidades educacionales de los adolescentes en Brasil y México

El objetivo de este artículo es examinar tendencias recientes de estratificación educacional en adolescentes de Brasil y México durante tres períodos distintos: la década de 1980, de severa recesión; los años de la década de 1990, un período de ajustes estructurales; y los años de la década del 2000 , la denominada de crecimiento. Además de matrículas escolares, y probabilidades de transiciones educacionales, se examina también la matrícula en escuelas privadas, un aspecto importante de la desigualdad educacional poco abordado en estudios sobre el tema. Se utilizaron datos de las PNADs sobre Brasil y ENIGH sobre México. Los resultados confirman importantes beneficios, atraídos por las condiciones recientes favorables y por la universalización de la enseñanza fundamental, a la par que también identifican crecientes desventajas, asociadas al acceso a la escuela privada, lo que sugiere la importancia de la perspectiva EMI (EffectivelyMaintained Inequality). El estudio enfatiza la importancia de analizar la calidad, además de la cantidad, de enseñanza formal para conseguir una comprensión más profunda de la estratificación educacional.

Palabras-clave: Desigualdad educacional. Juventud. Brasil. México.

\section{Abstract \\ Inequalities in educational opportunities of adolescents in Brazil and Mexico}

The aim of this paper is to examine recent trends in educational stratification for adolescents in Brazil and in Mexico in three distinct periods: the 1980s, years of severe recession, the 1990s, a period of structural adjustment, and the 2000s, a decade of growth. In addition to school enrollment and educational transitions, we also examined enrollment in private schools, an important aspect of educational inequality rarely addressed in studies on this topic. We used nationally representative data from the PNAD for Brazil and ENIGH for Mexico. Our findings confirm the significant benefits brought by recent improved conditions of universal primary education, but also identify increasing disadvantages associated with access to private schools, suggesting the importance of the EMI perspective (Effectively Maintained Inequality). The study emphasizes the importance of examining the quality in addition to the quantity of formal education for a deeper understanding of educational stratification in both Brazil and Mexico.

Keywords: Educational Inequality. Youth. Brazil. Mexico.

Recebido para publicação em 21/07/2012 Aceito para publicação em 22/08/2012 


\section{ANEXO}

Transições educacionais de adolescentes de 15 a 18 anos Brasil e México - 1976-2009

\begin{tabular}{|c|c|c|c|c|c|c|c|c|c|c|c|c|}
\hline \multirow{3}{*}{ Anos } & \multirow{2}{*}{\multicolumn{2}{|c|}{$\begin{array}{l}\text { Frequência à } \\
\text { escola (\%) }\end{array}$}} & \multicolumn{4}{|c|}{$\begin{array}{l}\text { Conclusão do ensino } \\
\text { fundamental (\%) }\end{array}$} & \multicolumn{4}{|c|}{$\begin{array}{c}\text { Transição para } \\
\text { o ensino médio (\%) }\end{array}$} & \multirow{2}{*}{\multicolumn{2}{|c|}{$\begin{array}{l}\text { Média de anos } \\
\text { de escolaridade }\end{array}$}} \\
\hline & & & \multicolumn{2}{|c|}{ Incondicional } & \multicolumn{2}{|c|}{ Condicional } & \multicolumn{2}{|c|}{ Incondicional } & \multicolumn{2}{|c|}{ Condicional } & & \\
\hline & México & Brasil & México & Brasil & México & Brasil & México & Brasil & México & Brasil & México & Brasil \\
\hline 1976 & & 46,11 & & 14,82 & & 17,29 & & 8,86 & & 55,99 & & 4,21 \\
\hline 1977 & & 46,66 & & 15,82 & & 18,19 & & 8,53 & & 50,13 & & 4,26 \\
\hline 1978 & & 47,80 & & 17,66 & & 20,37 & & 9,71 & & 50,72 & & 4,38 \\
\hline 1979 & & 49,22 & & 18,34 & & 21,29 & & 10,29 & & 50,68 & & 4,53 \\
\hline 1981 & & 49,12 & & 19,85 & & 22,21 & & 11,10 & & 53,26 & & 4,68 \\
\hline 1982 & & 46,98 & & 19,32 & & 21,52 & & 10,88 & & 53,24 & & 4,66 \\
\hline 1983 & & 48,17 & & 20,23 & & 22,27 & & 11,33 & & 53,41 & & 4,78 \\
\hline 1984 & 52,07 & 47,87 & 79,50 & 20,23 & 81,61 & 22,30 & 16,99 & 11,40 & 41,78 & 53,61 & 7,27 & 4,78 \\
\hline 1985 & & 48,34 & & 20,68 & & 22,66 & & 11,30 & & 51,76 & & 4,86 \\
\hline 1986 & & 47,99 & & 21,15 & & 23,14 & & 11,67 & & 52,11 & & 4,91 \\
\hline 1987 & & 47,77 & & 21,52 & & 23,39 & & 11,75 & & 51,73 & & 4,95 \\
\hline 1988 & & 50,23 & & 22,03 & & 23,87 & & 12,39 & & 53,18 & & 5,01 \\
\hline 1989 & 45,94 & 50,80 & 83,62 & 22,92 & 88,41 & 24,70 & 17,72 & 13,18 & 36,21 & 54,45 & 7,44 & 5,11 \\
\hline 1990 & & 52,14 & & 22,58 & & 24,34 & & 12,87 & & 53,74 & & 5,09 \\
\hline 1992 & 49,71 & 55,21 & 87,36 & 24,59 & 89,41 & 26,50 & 21,42 & 14,27 & 39,82 & 54,47 & 7,81 & 5,23 \\
\hline 1993 & & 57,64 & & 25,92 & & 27,69 & & 15,22 & & 54,90 & & 5,31 \\
\hline 1994 & 46,47 & & 84,51 & & 89,16 & & 20,98 & & 40,76 & & 7,59 & \\
\hline 1995 & & 62,08 & & 28,65 & & 30,34 & & 17,09 & & 55,88 & & 5,55 \\
\hline 1996 & 49,84 & 64,63 & 86,06 & 31,68 & 89,73 & 33,49 & 21,91 & 19,48 & 40,68 & 57,80 & 7,78 & 5,79 \\
\hline 1997 & & 67,96 & & 33,40 & & 34,84 & & 20,36 & & 57,38 & & 5,91 \\
\hline 1998 & 50,53 & 71,27 & 88,55 & 37,66 & 91,87 & 39,04 & 25,01 & 23,81 & 45,46 & 59,75 & 7,98 & 6,18 \\
\hline 1999 & & 73,59 & & 41,39 & & 42,58 & & 26,14 & & 60,21 & & 6,45 \\
\hline 2000 & 54,21 & & 90,42 & & 92,67 & & 28,77 & & 47,27 & & 8,28 & \\
\hline 2001 & & 75,09 & & 46,99 & & 48,07 & & 30,22 & & 60,96 & & 6,82 \\
\hline 2002 & 57,71 & 75,46 & 91,94 & 49,79 & 94,36 & 50,83 & 29,53 & 32,21 & 44,46 & 62,14 & 8,47 & 6,98 \\
\hline 2003 & & 76,24 & & 53,16 & & 54,11 & & 34,56 & & 62,29 & & 7,20 \\
\hline 2004 & 56,90 & 75,21 & 92,90 & 54,89 & 94,84 & 55,78 & 35,27 & 36,23 & 52,10 & 63,56 & 8,70 & 7,30 \\
\hline 2005 & 58,35 & 74,51 & 94,25 & 56,70 & 95,70 & 57,55 & 35,04 & 37,81 & 50,41 & 64,53 & 8,78 & 7,43 \\
\hline 2006 & 59,96 & 74,65 & 95,30 & 58,24 & 96,31 & 58,91 & 36,36 & 38,83 & 50,44 & 64,46 & 8,93 & 7,52 \\
\hline 2007 & & 73,86 & & 60,56 & & 62,16 & & 40,98 & & 65,28 & & 7,70 \\
\hline 2008 & 62,30 & 75,88 & 95,67 & 61,00 & 96,37 & 63,48 & 37,97 & 41,64 & 51,54 & 65,93 & 9,04 & 7,72 \\
\hline 2009 & & 76,96 & & 61,40 & & 64,50 & & 41,12 & & 65,17 & & 7,76 \\
\hline
\end{tabular}

Fonte: IBGE. PNADs 1976-2009; ENIGH 1984-2008. 